\title{
Coordinated interhemispheric SuperDARN radar observations of the ionospheric response to flux transfer events observed by the Cluster spacecraft at the high-latitude magnetopause
}

\author{
J. A. Wild ${ }^{1}$, S. E. Milan ${ }^{1}$, S. W. H. Cowley ${ }^{1}$, M. W. Dunlop ${ }^{2, \dagger}$, C. J. Owen ${ }^{3}$, J. M. Bosqued ${ }^{4}$, M. G. G. T. Taylor ${ }^{3, *}$, \\ J. A. Davies ${ }^{1}$, M. Lester ${ }^{1}$, N. Sato ${ }^{5}$, A. S. Yukimatu ${ }^{5}$, A. N. Fazakerley ${ }^{3}$, A. Balogh ${ }^{2}$, and H. Rème (,† $^{4}$ \\ ${ }^{1}$ Department of Physics \& Astronomy, University of Leicester, Leicester LE1 7RH, UK \\ ${ }^{2}$ Blackett Laboratory, Imperial College, London SW7 2BZ, UK \\ ${ }^{3}$ Mullard Space Science Laboratory, University College London, Holmbury St. Mary, Dorking, Surrey RH5 6NT, UK \\ ${ }^{4}$ CESR, BP 4346, 31028 Toulouse 4, France \\ ${ }^{5}$ National Institute of Polar Research, Tokyo 173-8515, Japan \\ * now at: Los Alamos National Laboratory, Los Alamos, NM 87545, USA \\ †now at: Rutherford Appleton Laboratory, Chilton, Didcot, Oxfordshire, OX11 0QX, UK
}

Received: 28 October 2002 - Revised: 10 March 2003 - Accepted: 25 March 2003

\begin{abstract}
At 10:00 UT on 14 February 2001, the quartet of ESA Cluster spacecraft were approaching the Northern Hemisphere high-latitude magnetopause in the post-noon sector on an outbound trajectory. At this time, the interplanetary magnetic field incident upon the dayside magnetopause was oriented southward and duskward ( $B_{Z}$ negative, $B_{Y}$ positive), having turned from a northward orientation just over 1 hour earlier. As they neared the magnetopause the magnetic field, electron, and ion sensors on board the Cluster spacecraft observed characteristic field and particle signatures of magnetospheric flux transfer events (FTEs). Following the traversal of a boundary layer and the magnetopause, the spacecraft went on to observe further signatures of FTEs in the magnetosheath. During this interval of ongoing pulsed reconnection at the high-latitude post-noon magnetopause, the footprints of the Cluster spacecraft were located in the fields-of-view of the SuperDARN Finland and Syowa East radars located in the Northern and Southern Hemispheres, respectively. This study extends upon the initial survey of Wild et al. (2001) by comparing for the first time in situ magnetic field and plasma signatures of FTEs (here observed by the Cluster 1 spacecraft) with the simultaneous flow modulations in the conjugate ionospheres in the two hemispheres. During the period under scrutiny, the flow disturbances in the conjugate ionospheres are manifest as classic "pulsed ionospheric flows" (PIFs) and "poleward moving radar auroral forms" (PMRAFs). We demonstrate that the ionospheric flows excited in response to FTEs at the magnetopause are not those expected for a spatially limited reconnection region, somewhere in the vicinity of the Cluster 1 spacecraft. By examining the large- and small-scale flows in the high-latitude ionosphere, and the inter-hemispheric correspondence exhibited during this interval, we conclude that the reconnection processes that result in the generation of PIFs/PMRAFs must
\end{abstract}

Correspondence to: J. A. Wild (j.wild@ion.le.ac.uk) extend over many (at least 4) hours of magnetic local time on the pre- and post-noon magnetopause.

Key words. Ionosphere (plasma convection) - Magnetospheric physics (magnetosphere-ionosphere interactions; magnetospheric configuration and dynamics)

\section{Introduction}

The exact nature of the coupling mechanism between the solar wind and the Earth's magnetosphere remains one of the key outstanding questions in solar-terrestrial physics. Observations supporting the supposition that reconnection processes at the high-latitude magnetopause are frequently transient in nature were first presented by Haerendel et al. (1978), exploiting magnetic field measurements from the HEOS-2 spacecraft. Using lower latitude magnetic field observations from the ISEE-1 and 2 spacecraft, Russell and Elphic (1978, 1979) also reported transient signatures of magnetic reconnection at the magnetopause with time scales of a few minutes and a recurrence interval of $\sim 5-10 \mathrm{~min}$, and it was these authors that went on to term these transient signatures "flux transfer events" (FTEs). These transients are usually characterised by bipolar signatures in the magnetic field component normal to the magnetopause (sometimes associated with field tilting effects in the plane of the magnetopause) and a mixed plasma population of both magnetospheric and magnetosheath origin (e.g. Paschmann et al., 1982; Farrugia et al., 1988). The physical interpretation of FTEs offered by Russell and Elphic $(1978,1979)$ was based upon transient (few minute) and spatially localised (few $R_{E}$ ) intervals of magnetic reconnection at the magnetopause, an interpretation that was subsequently supported by several studies showing that FTEs were most frequently observed during intervals with southward directed fields in the magnetosheath 
(e.g. Rijnbeek et al., 1984; Berchem and Russell, 1984; Kawano and Russell, 1997). The size, longevity and evolution of the reconnection site from which FTEs originate has been the subject of much debate; for example, Southwood et al. (1988) and Scholer (1988) postulated that the transient reconnection region extends significantly further over the magnetopause surface than was originally suggested by Russell and Elphic (1978, 1979) whilst Milan et al. (2000), drawing upon UV auroral imager data and HF radar data, suggested that the reconnection site may at any one time be spatially localised, but that it propagates wave-like over the magnetopause for extended distances and intervals of time (at least $\sim 10$ min).

Clearly, the dayside ionospheric flow response to reconnection processes at the magnetopause will depend upon the prevailing reconnection geometry at the boundary, and a range of theoretical descriptions have been proposed to describe the expected flow signatures that would result from patchy, extended, or wave-like reconnection sites (e.g. Southwood, 1985, 1987; Cowley, 1986; McHenry and Clauer, 1987; Lockwood et al., 1990; Wei and Lee, 1990; Cowley et al., 1991; Cowley and Lockwood, 1992; Milan et al., 2000). Motivated by the potential to exploit ionospheric observations in order to diagnose reconnection processes at the magnetopause, a great deal of effort has been made to observe the signatures of FTEs in the high-latitude ionosphere. Among the first ground-based measurements to be interpreted as potential flux transfer events were those of van Eyken et al. (1984), who reported a brief northward excursion in a westward flow region observed by the EISCAT UHF incoherent scatter radar. Subsequently, Lockwood et al. (1989, 1993) associated ionospheric flow enhancements observed by the EISCAT system with dayside auroral transients that related to FTEs observed at the magnetopause. In recent years high frequency (HF) coherent radars have provided a wealth of observations that have been associated with flux transfer events. HF radars often observe high velocity antisunward transient flow in the cusp ionosphere and it was these signatures that were interpreted as the response to transient magnetopause reconnection by Pinnock et al. (1993, 1995) and Rodger and Pinnock (1997). Subsequently, quasi-periodic sequences of such events, often termed "pulsed ionospheric flows" (PIFs), have been reported and examined both individually (Provan et al., 1998) and statistically (Provan and Yeoman, 1999). These are often also seen as poleward-moving regions of enhanced backscatter power, the radar counterpart of "poleward-moving auroral forms" (PMAFs), widely accepted to be the auroral signature of FTEs (e.g. Sandholt et al., 1990; Thorolfsson et al., 2000). In the text below we will refer to these radar PMAFs as "poleward-moving radar auroral forms" or PMRAFs. As noted by Wild et al. (2001), care should be taken in the use of "PIF" and "PMRAF" nomenclature, which are often erroneously used interchangeably. It is not always possible to say whether isolated PMRAFs are associated with a PIF or not, as no measurements of the ionospheric flow preceding or following the PMRAF are made (as no backscatter is ob- served). The lack of backscatter before or after the PMRAF does not necessarily indicate that a change in convection flow has occurred, only that no targets were present from which the radar could scatter. However, the almost continuous observations of the polar ionosphere provided by HF coherent radars have enabled the spatial extent of these events, their flow orientation, MLT occurrence, dependence on IMF orientation, and repetition frequencies to be extensively examined (Provan et al., 1998, 1999; Provan and Yeoman, 1999; Milan et al., 1999, 2000; McWilliams et al., 2000).

Employing ionospheric flow observations from the EISCAT radar system and magnetic field measurements from the ISEE-1 and -2 spacecraft, Elphic et al. (1990) presented the first simultaneous observations of an FTE at the magnetopause and the flow response in the near-conjugate ionosphere. More recently, Neudegg et al. (1999) presented the first coordinated space- and ground-based study of FTEs to exploit measurements from a HF coherent radar system. During the case study presented, a southward turning of the IMF resulted in the observation of a clear magnetospheric FTE in the magnetometer data of the Equator-S spacecraft, located in the vicinity of the low-latitude morning-sector magnetopause. The timing of the observed FTEs closely matched the onset of transient poleward-propagating flow features in the SuperDARN Hankasalmi (CUTLASS) radar. It is worth noting that since this study employed data acquired using a non-standard radar mode, the ionospheric flow data presented was of exceptionally high quality with better than usual spatial and temporal resolution. This allowed the authors to accurately deduce the resulting ionospheric convection, which proved to be consistent with previous HF radar results based solely upon ground-based data. Neudegg et al. (2001) went on to show that the high-latitude convection response to the reconnection process associated with this magnetopause FTE excited strong UV aurora equatorward of the footprint of the newly-reconnected field lines. By carrying out a statistical survey of FTEs observed in the vicinity of the magnetopause by the Equator-S spacecraft, Neudegg et al. (2000) found a strong association with the characteristic pulsed antisunward flows observed in the HF radar data at the conjugate ionospheric footprint of the spacecraft. They went on to suggest that for FTEs with a repetition rate of greater than $\sim 5 \mathrm{~min}$, a clear one-to-one correlation often existed between magnetopause and ionospheric events. For faster repetition rates, the ionospheric response began to resemble that expected from a continuous flow excitation. The overall flow patterns observed in association with the FTEs were in broad agreement with those predicted theoretically, but showed a wide variety of responses on an event-to-event basis.

Combining, for the first time, magnetic field observations from the ESA Cluster mission and ground-based coherentand incoherent-scatter radar measurements of the ionospheric flow in the region of the dayside cusp, Wild et al. (2001) presented simultaneous observations of FTEs at the high-latitude magnetopause and pulsed radar signatures in the conjugate Northern Hemisphere ionosphere. More specifically, transient bipolar signatures in the magnetic field 
component normal to the magnetopause, characteristic of FTEs at the high-latitude magnetopause, were observed to coincide with pulsations in the ionospheric flow at the latitude of the Cluster footprint measured by the Hankasalmi SuperDARN (CUTLASS) HF radar. The radar features pulsated in both velocity and backscatter power and were observed propagating poleward, forming classic "pulsed ionospheric flow" (PIFs) and "poleward-moving radar auroral forms" (PMRAFs) at higher latitudes. Furthermore, Wild et al. (2001) demonstrated an excellent correspondence between the FTEs observed at the magnetopause and the pulsations in the dawnward component of the ionospheric flow despite the radar measurements being displaced by some $2 \mathrm{~h}$ of MLT to the west of the estimated location of the Cluster footprint. Considering the expected dawnward and poleward motion of reconnected flux tubes in the Northern Hemisphere post-noon magnetosphere due to the duskward and southward directed IMF during the interval presented, it was suggested by Wild et al. (2001) that the lower latitude westward flow region corresponded to newly-opened flux tubes in which the first influences of each burst of reconnection were felt. In addition, an apparent relationship between the zonal ionospheric flow modulation and PIF/PMRAF signatures at higher latitudes was reported. More specifically, enhancements in backscattered power observed in the lower-latitude westward flow region generally preceded PIF or PMRAF signatures at higher latitudes, implying that the PIF/PMRAF events originated near a latitude of $74^{\circ}-75^{\circ}$ (close to the latitude of the Cluster footprint) and propagated poleward to $\sim 80^{\circ}$ where they resembled the more classic PIF/PMRAF signatures. An association between flow changes at lower latitudes and PMRAF features at higher latitudes had previously been reported in studies by Milan et al. (2000) and Davies et al. (2002). Consequently, Wild et al. (2001) went on to concluded that PMRAFs are "fossils" of the ionospheric structuring that takes place at the ionospheric footprint of the dayside merging gap and as such are useful tracers of the convection flow on newly-reconnected field lines. The occurrence of these fossils in relation to PIFs may yield information regarding the level of inductive smoothing of the flow being excited by the reconnection process. Significantly, it was suggested that the observation of a PMRAF might be delayed from its associated burst of reconnection by up to several minutes.

The data presented in Wild et al. (2001) (hereafter referred to as Paper 1), were drawn from the first two weeks of Cluster science operations and constituted a "first results" overview of the interval $09: 15-11: 15$ UT on 14 February 2001. Since the preparation of Paper 1 a substantially extended dataset, from both space- and ground-based instruments, has become available and has allowed for a more comprehensive investigation of the interval to be undertaken. This paper will present hitherto unique simultaneous interhemispheric ground-based observations of the response to FTEs observed at the magnetopause by Cluster; a comprehensive multi-spacecraft, multi-instrument in situ study of the FTEs observed at the high-latitude magnetopause during this interval will be presented in a future companion paper.

\section{Instrumentation}

\subsection{SuperDARN radar data}

The Super Dual Auroral Radar Network (SuperDARN) (Greenwald et al., 1995) comprises 15 HF coherent-scatter radars covering a large fraction of the auroral zone and polar cap in each hemisphere (nine in the Northern Hemisphere and six in the Southern Hemisphere). Each radar is frequency agile in the range $8-20 \mathrm{MHz}$, although they most commonly operate at frequencies in the $10-14 \mathrm{MHz}$ range, scattering multi-pulse sequences of HF radio waves from decametre scale electron density irregularities in the E- and Fregion ionosphere. By employing phased arrays of antennas, the radars are able to electronically steer the transmitted pulse sequence, sounding 16 beams (each separated by $3.24^{\circ}$ in azimuth) with each beam subdivided into 75 range gates. During the interval of interest, all 15 SuperDARN radars were operating in a common mode in which each beam was sounded for $3 \mathrm{~s}$, thus completing a full scan of all 16 beams (some $52^{\circ}$ in aziumth) every $1 \mathrm{~min}$, the shortfall being used for the processing and recording of data and to enable all fifteen radars to "synchronize" and begin successive scans at predetermined times (such as minute boundaries). The length of each of the 75 gates was set to $45 \mathrm{~km}$ with a range to the first gate of $180 \mathrm{~km}$. In addition to measuring the backscattered power received at the radar, Doppler spectra are obtained by analysing the autocorrelation function of the returned signals, from which the mean Doppler velocity, an estimate of the line-of-sight (1-o-s) plasma velocity, and Doppler spectral width are derived.

This study presents 1-o-s backscattered power and Doppler velocity observations from two SuperDARN radars, namely the Finland and Syowa East radars. The Finland radar is located at Hankasalmi $\left(62.3^{\circ} \mathrm{N}, 26.6^{\circ} \mathrm{E}\right)$ and forms part of the Co-operative UK Twin Located Auroral Sounding System (CUTLASS); the Syowa East radar is sited close to the Syowa station $\left(69.0^{\circ} \mathrm{S}, 39.6^{\circ} \mathrm{E}\right)$ in Antarctica. Figure 1 presents the fields-of-view (f-o-v) of these radars in an MLTmagnetic latitude coordinate system. The north magnetic pole lies at the centre of the figure with lines of constant magnetic latitude at $10^{\circ}$ increments indicated by concentric dotted circles. The dotted radial lines represent meridians of magnetic local time at one hour increments, with magnetic midnight (noon) being located at the bottom (top) of the figure and dawn (dusk) located on the right-(left-) hand side. For reference, the statistical location of the auroral oval (Feldstein and Starkov, 1967) for the appropriate level of geomagnetic activity $\left(K_{p}=4\right)$ and the coastlines of the Northern Hemisphere land masses at 10:20 UT on 14 February 2001 have been overlaid. The overall f-o-v of the Finland radar at this time is represented by the solid blue lines with the locations of three individual beams discussed in detail below indicated by dot-dashed blue lines and numbered accord- 


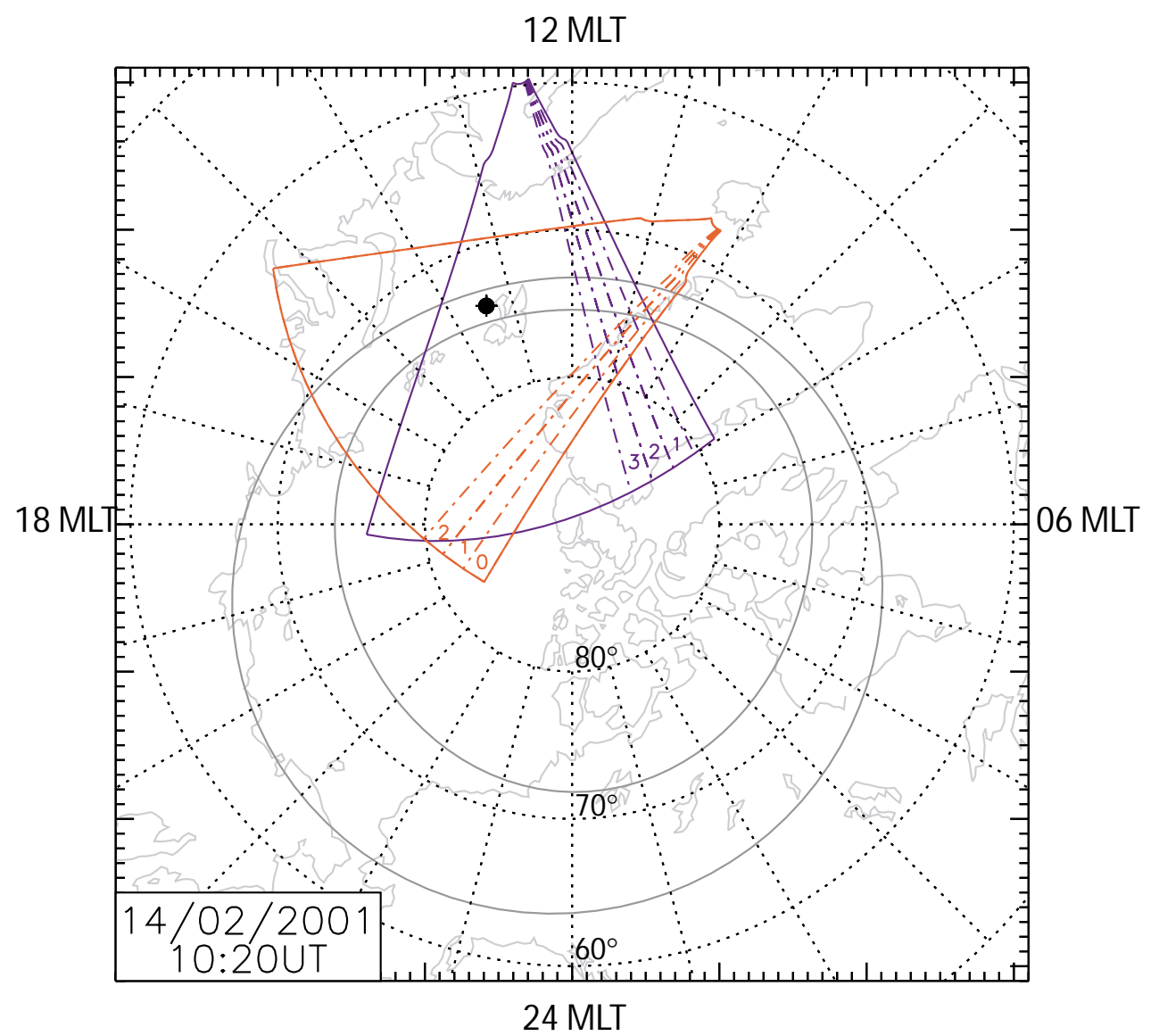

Fig. 1. A magnetic latitude-magnetic local time projection of the Northern Hemisphere at 10:20 UT on 14 February 2001. Lines of constant geomagnetic latitude, starting at $80^{\circ} \mathrm{N}$ and then at $10^{\circ}$ intervals, are indicated by dotted concentric circles. Magnetic local time meridians at $1 \mathrm{~h}$ intervals are also indicated by dotted lines with magnetic noon (midnight) located at the top (bottom) of the figure and dawn (dusk) located on the right- (left-) hand side. The Northern Hemisphere coastlines at this time are indicated in light grey and the statistical location of the auroral oval $\left(K_{p}=4\right)$ by solid dark grey lines. The overall field-of-view of the SuperDARN Finland radar is shown by the solid indigo lines. The individual beams within the field-of-view referred to in the text are bounded by dot-dashed lines and numbered appropriately. Similarly, the field-of-view and specific beams of the Southern Hemisphere SuperDARN Syowa East radar, mapped into the Northern Hemisphere, are also indicated by red solid and dot-dashed lines, respectively. The Northern Hemisphere ionospheric footprint of the Cluster 1 spacecraft at this time is indicated by the crossed circle.

ingly. Similarly, the overall f-o-v and three individual beams of the Southern Hemisphere Syowa East radar, mapped into the Northern Hemisphere, are indicated by red solid and dotdashed lines respectively. Finally, the magnetic footprint of the Cluster 1 spacecraft at 10:20 UT on 14 February 2001 is shown in Fig. 1 by the black crossed circle. This footprint was mapped from the location of the Cluster 1 spacecraft using the Tsyganenko-96 magnetic field model (Tsyganenko 1995, 1996) and parameterised as discussed below.

In addition to the measurements of 1-o-s Doppler velocity from the Finland and Syowa East radars, observations of ionospheric flow from all the available SuperDARN radars (in both hemispheres) are employed to estimate the largescale ionospheric convection pattern using the "map potential" technique of Ruohoneimi et al. $(1996,1998)$. This technique is discussed more fully below.

\subsection{ACE interplanetary data}

The IMF and solar wind parameters required for this study were measured by the MAG and SWEPAM instruments respectively, on board the Advanced Composition Explorer (ACE) spacecraft (McComas et al., 1998; Smith et al., 1998; Stone et al., 1998), located some $237 R_{E}$ upstream from the Earth during the interval of interest. The propagation delay between field signatures appearing at the ACE spacecraft and their arrival at the subsolar magnetopause has been estimated using the technique of Khan and Cowley (1999). In summary, this method takes into account the propagation of IMF features with the solar wind to the bow shock and then across the magnetosheath to the magnetopause, using empirical model values of the location of these boundaries controlled by the observed solar wind parameters. For conditions during the period of interest $\left(n_{S W} \sim 1-3 \mathrm{~cm}^{-3}\right.$, $V_{S W} \sim 500 \mathrm{~km} \mathrm{~s}^{-1}$ ), the propagation delay is determined to be 
$\sim 55$ min. For example, the IMF and solar wind parameters input to the magnetic field and boundary models presented in Fig. 2 and corresponding to 10:20 UT on 14 February 2001 are those measured at the ACE spacecraft at 09:25 UT on the same date, these being $P_{\text {dyn }}=1.5 \mathrm{nPa}$, IMF $B_{Y}=2.8 \mathrm{nT}$, and IMF $B_{Z}=-2.5 \mathrm{nT}$. Similarly, the ACE data presented below have been lagged by $55 \mathrm{~min}$ so that they may be compared with Cluster observations near the magnetopause. The appropriate values of the Dst and $K_{p}$ indices at the time were $37 \mathrm{nT}$ and 4 , respectively, indicating moderate levels of geomagnetic activity.

\subsection{Cluster data}

Figure 2 presents the motion of the Cluster 1 (Rumba) spacecraft in the GSM $X-Z$ plane during the interval from 14:00 UT on 13 February 2001 to 18:00 UT on 14 February 2001. At this time, the apogee of the Cluster orbit was located at around 13:00 MLT, with the spacecraft passing through slightly earlier local times during their inbound motion in the Southern Hemisphere and slightly later local times in the Northern Hemisphere moving outbound from perigee. The locations of the Cluster 1,2,3, and 4 spacecraft relative to the Cluster 1 orbital path at 10:20 UT on 14 February 2001 are indicated by indigo, green, yellow and red filled circles, respectively. The inter-spacecraft separation has been exaggerated by a factor of 20 , in order to emphasise the tetrahedral configuration of the quartet during this interval. A cut though a Shue et al. (1997) model magnetopause at the approximate location of the Cluster 1 spacecraft out of the GSM $X-Z$ plane $\left(Y_{\mathrm{GSM}} \approx 3.9 R_{E}\right)$ at 10:20 UT is indicated by the dashed indigo line. The magnetospheric field passing through the Cluster 1 spacecraft at this time inferred from the Tsyganenko-96 field model (Tsyganenko 1995, 1996) is also included, represented by the dotted black line. Both the model magnetopause location and magnetospheric field line model are parameterised by solar wind and IMF conditions. The Shue et al. (1997) magnetopause location and shape is controlled by the solar wind dynamic pressure $P_{\mathrm{dyn}}$, and the $B_{Z}$ component of the IMF whilst the Tsyganenko-96 field model utilises these and a further two parameters, namely the $B_{Y}$ component of the IMF and the $D_{s t}$ index. Consequently, the solar wind and IMF parameters employed to generate this figure are those quoted above.

The Cluster fluxgate magnetometer (FGM) experiment (Balogh et al., 1997, 2001) comprises two triaxial fluxgate magnetic field sensors on each of the four spacecraft (eight in total). In normal operation the outboard sensor, located at the end of a $5 \mathrm{~m}$ boom, is used as the primary source of data. The FGM sensors are calibrated such that the local magnetic field vector can be measured with an accuracy approaching $0.1 \mathrm{nT}$ at high sample rates (up to 67 vectors s $^{-1}$ ). The FGM magnetic field data presented in this study were recorded by spacecraft 1 (Rumba) and have been analysed at a temporal resolution equal to the spin period of the spacecraft $(\sim 4 \mathrm{~s})$.

Observations of the ion populations encountered by the Cluster spacecraft are provided by the Cluster Ion Spectrom-

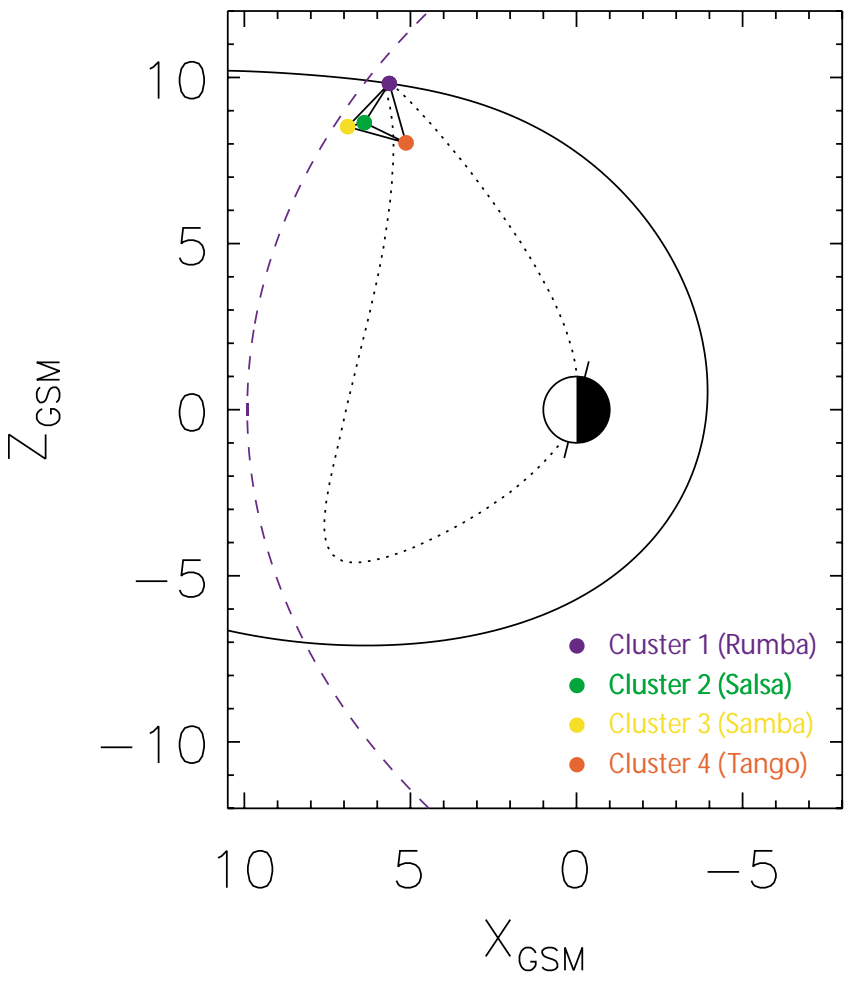

Fig. 2. Plot showing the projection of the orbit of the Cluster 1 (Rumba) spacecraft on to the GSM $X-Z$ plane during the interval 14:00 UT on 13 February 2001 to $18: 00$ UT on 14 February 2001. The relative locations of the four spacecraft at 10:20 UT on 14 February are indicated by coloured circles, as described by the key, where the separation from Cluster 1 has been magnified by a factor of 20 , in order to more clearly demonstrate the tetrahedral formation. This time also corresponds the Northern Hemisphere map presented in Fig. 1. A Tsyganenko-96 model field line, as described in the text, has been drawn from the location of the Cluster 1 spacecraft (black dotted line). In addition, a cut through the model magnetopause at $Y_{\mathrm{GSM}} \approx 3.9 R_{E}$ (the approximate location of Cluster 1 at 10:20 UT) is indicated by the dashed blue line, whilst the orientation of the Earth's magnetic dipole is indicated by the short black lines.

etry (CIS) experiment (Rème et al., 1997, 2001). This instrument is able to measure the full three-dimensional ion distribution of the major magnetospheric ions, namely $\mathrm{H}^{+}, \mathrm{He}^{+}$, $\mathrm{He}^{++}$, and $\mathrm{O}^{+}$, from thermal energies to about $40 \mathrm{keV} / \mathrm{e}$. The CIS experiment on board each of the Cluster spacecraft comprises two separate instruments: a COmposition and DIstribution Functions analyser (known as CODIF or CIS1) and a Hot Ion Analyser (HIA/CIS2). The CODIF instrument is capable of measuring the mass per charge composition of the ion population with medium $\left(22.5^{\circ}\right)$ angular resolution, whereas the HIA instrument offers no mass resolution but has superior angular resolution $\left(5.6^{\circ}\right)$. The CIS data presented below were recorded by the HIA instrument on board the Cluster 1 spacecraft and are presented at two different temporal resolutions. First, moments of the threedimensional distribution yielding the total ion number den- 
sity (assuming that all measured ions are $\mathrm{H}^{+}$) are calculated on board the spacecraft at spin $(\sim 4 \mathrm{~s})$ resolution; secondly, energy-time ion spectrograms are retrospectively generated from the three-dimensional distributions acquired over three spins of the spacecraft (12s).

The electron observations in the vicinity of the highlatitude magnetopause included in this study were made by the Cluster Plasma Electron And Current Experiment (PEACE) (Johnstone et al., 1997; Owen et al., 2001). Each PEACE instrument (one per spacecraft) is equipped with two sensor heads, a Low- and a High-Energy Electron Analyser (LEEA and HEEA, respectively), which are mounted on opposite sides of the spacecraft, each of which is capable of measuring electrons in the energy range $0.7 \mathrm{eV}$ to $\sim 30 \mathrm{keV}$, arriving from all directions during a spacecraft spin. During the interval presented, the PEACE instrument was configured such that each sensor measured a subset of the maximum possible energy range with HEEA covering the upper part of the energy range. Accordingly, the PEACE data included below shows electron fluxes averaged over all look-directions of the HEEA sensor on board the Cluster 1 spacecraft and has a temporal resolution equal to the spacecraft spin period $(\sim 4 s)$.

\section{Observations}

This paper focuses on ground-based radar observations of the ionosphere, in both hemispheres, during a period when magnetic reconnection was occurring at the high-latitude dayside magnetopause, characterised by the observation of a series of FTEs by the Cluster spacecraft. In order to examine the ionospheric response to the inferred magnetospheric dynamics, it is first necessary to present the in situ observations of FTEs in the vicinity of the magnetopause, and then show the ground-based observations of the ionospheric flows that subsequently arose. However, as the in situ field and plasma observations introduced in this section will be the subject of a rigorous, multi-spacecraft, multi-instrument investigation to be published in a future companion study, this paper will present an overview of the in situ data drawn from one Cluster spacecraft only (Cluster 1).

\subsection{Cluster observations}

Figure 3 presents observations of the local magnetic field and particle environment at the Cluster 1 spacecraft during the interval 09:15-11:15 UT on 14 February 2001, which includes the outbound passage from the magnetosphere to the magnetosheath. Also displayed (upper panel) is the clock angle of the IMF measured upstream of the Earth and lagged by $55 \mathrm{~min}$, as discussed above. Since the upstream IMF conditions and the magnetic field measured by the four Cluster spacecraft during this passage were discussed in detail in $\mathrm{Pa}$ per 1 , only a short review is presented here, in order to place the newly available plasma observations in the context of the magnetic field and ground-based signatures of FTEs reported by Wild et al. (2001).

Immediately prior to the interval discussed here, the IMF was oriented northward with a significant dawnward component ( $B_{Y}$ negative, $B_{Z}$ positive). Following a reorientation at around 08:53 UT (lagged time) the IMF was directed predominantly southward $\left(B_{Z} \sim-3 \mathrm{nT}\right)$ and duskward $\left(B_{Y} \sim 5 \mathrm{nT}\right)$ during the interval presented, with corresponding IMF clock angles in the range $90-180^{\circ}$, with the exception of a few brief excursions into northward or dawnward orientations. The magnitude of the IMF remained generally steady throughout, varying slightly between $6 \mathrm{nT}$ at the beginning of the interval and $5 \mathrm{nT}$ toward the end.

The three panels beneath the ACE IMF data present observations from the FGM instrument on board the Cluster 1 spacecraft. As is usual when presenting magnetic field observations from the region adjacent to the magnetopause, the data are presented in a boundary-normal coordinate system (Russell and Elphic, 1978), where $\boldsymbol{N}$ is the estimated outward normal to the magnetopause, $\boldsymbol{L}$ lies in the boundary and points north (such that the $L-N$ plane contains the GSM $Z$ axis), and $\boldsymbol{M}$ also lies in the boundary and points west, orthogonal to $\boldsymbol{L}$ and $N$ (such that $(L, M, N)$ forms a right-handed coordinate system). The first of these panels presents the $B_{N}$ component of the observed field, the second panel presents the total field magnitude, whilst the third panel shows the angle of the field in the plane of the magnetopause, $\alpha_{L M}$, defined as $\alpha_{L M}=\tan ^{-1}\left(B_{M} / B_{L}\right)$. In order to present magnetic field data in this coordinate system, it is, of course, first necessary to estimate the outward magnetopause normal direction. In order to obtain a representative outward normal direction for the magnetopause encountered during the central portion of the interval presented in Fig. 3, the minimum variance analysis technique (Sonnerup and Cahill, 1967) was applied to the interval 10:00-10:40 UT, yielding an outward unit normal given by GSM components $(+0.669,-0.262$, $+0.696)$. For a more detailed discussion regarding the determination of this normal direction, the reader is directed to Paper 1.

The fifth and sixth panels of Fig. 3 present the total ion concentration and energy-time spectrogram measured by the CIS HIA instrument on Cluster 1, respectively. Finally, the lower panel presents an energy-time spectrogram of electrons observed by the HEEA sensor of the PEACE instrument, also on board the Cluster 1 spacecraft.

At 09:15 UT on 14 February 2001 (the beginning of the interval shown in Fig. 3) the Cluster 1 spacecraft was located within the magnetosphere at a radial distance of approximately $10.9 R_{E}$ from the Earth and moving on an outbound trajectory toward the high-latitude post-noon magnetopause. The observed magnetospheric field strength at this time was $\sim 20 \mathrm{nT}$ and directed mainly southward and westward ( $B_{L}$ negative, $B_{M}$ positive), as expected in the vicinity of the post-noon cusp. By 11:15 UT, the Cluster 1 spacecraft had passed into the magnetosheath, the field being oriented southward and eastward ( $B_{L}$ and $B_{M}$ negative) which, although still $\sim 20 \mathrm{nT}$ in magnitude, is consistent with 


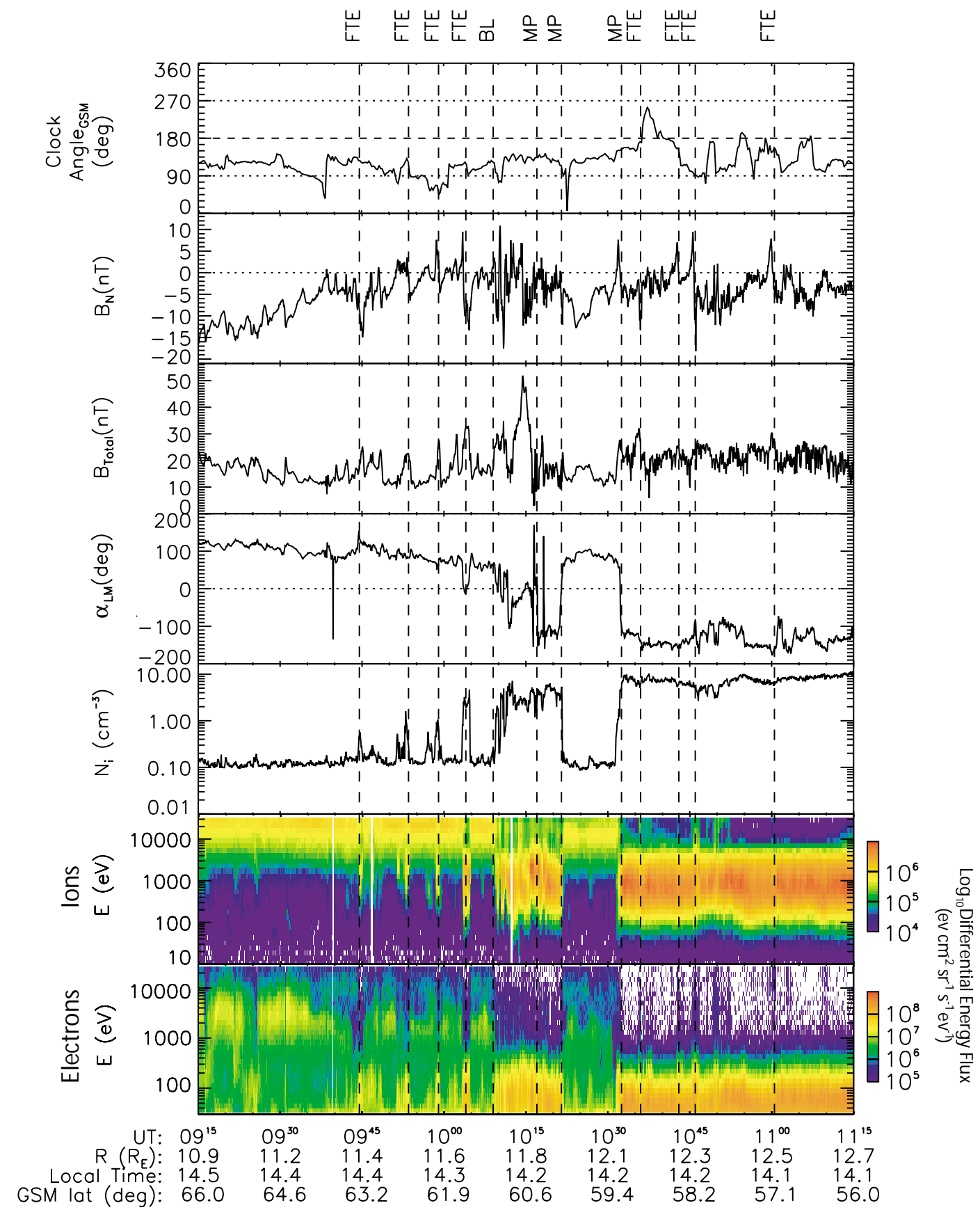

Fig. 3. Plot of ACE and Cluster data for the interval 09:15-11:15 UT on 14 February 2001. The top panel shows the clock angle of the interplanetary magnetic field measured at the ACE spacecraft and lagged by 55 min such that comparisons can be made with the Cluster observation at the front of the magnetosphere. The next three panels present the component of the magnetic field normal to the magnetopause, the total magnetic field strength, and the angle of the magnetic field in the plane of the magnetopause (the $\alpha_{L M}$ parameter) measured by the FGM instrument on board the Cluster 1 (Rumba) spacecraft. The fifth and sixth panels present the total ion density profile and ion energytime spectrogram (all pitch angles) observed by the CIS2 (HIA) instrument on Cluster 1. Finally, the lower panel presents the electron energy distribution measured in the field-parallel direction by the PEACE HEEA sensor, also on Cluster 1. Overlaid on this figure (dashed lines) are the times of events originally identified by Wild et al. (2001) and discussed in the text. Specifically, the centre times of four magnetospheric FTEs, the entry into the boundary layer (BL), three crossings of the magnetopause (MP), and four magnetosheath FTEs are indicated.

the expected orientation of the field in the magnetosheath based upon upstream IMF conditions. Plasma observations from the CIS and PEACE instruments also clearly indicate the transition from magnetosphere- to magnetosheath-like plasma over the interval presented. The magnetospheric ion concentration measured by CIS at the beginning of the 
interval was $\sim 0.1 \mathrm{~cm}^{-3}$, with the energy at the peak ion flux greater than $\sim 10 \mathrm{keV}$. This is compared to the observed ion concentration of $\sim 10 \mathrm{~cm}^{-3}$ in the magnetosheath, where the peak of ion energy distribution is significantly lower $(\sim 1 \mathrm{keV})$. This transition from a hot, tenuous plasma to a cooler, denser plasma was reflected in measurements of the electron population made by PEACE, which recorded a shift in the energy of the peak flux of the electron distribution from a few $\mathrm{keV}$ in the magnetosphere to several tens of $\mathrm{eV}$ in the magnetosheath.

The timings of several key features identified in Paper 1 are indicated by dashed lines in the central portion of the interval displayed in Fig. 3. At 10:09 UT, some 8 min prior to the first magnetopause encounter, the spacecraft encountered a boundary layer (marked "BL") in which the magnetic field became increasingly variable, but generally veered toward the direction of the field in the magnetosheath. Three clear magnetopause crossings followed (labelled "MP") occurring at $\sim 10: 17$ UT (magnetosphere-magnetosheath), $\sim 10: 22$ UT (magnetosheath-magnetosphere), and $\sim 10: 33$ UT (magnetosphere-magnetosheath).

Plasma observations, unavailable to us during the preparation of Paper 1, support our interpretation of three magnetopause transitions, the first of which was preceded by observations of a boundary layer lasting several minutes. At $\sim 10: 09$ UT CIS recorded an approximate factor of 20 increase in the ion concentration at the Cluster 1 spacecraft. Although variable over the next few minutes, this enhanced ion concentration peaked at $\sim 7 \mathrm{~cm}^{-3}$ before settling at slightly lower values until just prior to the first magnetopause crossing at $\sim 10: 17$ UT. This increase in concentration was accompanied by a marked change in the ion population energy distribution from magnetosphere-like $(\sim 10 \mathrm{keV})$ to more magnetosheath-like energies (several hundred $\mathrm{eV}$ to a few keV). Significant structure, some of which appears to be energy dispersed, is also apparent within the boundary layer. Following the first penetration of the magnetopause at $\sim 10: 17 \mathrm{UT}$, the observed plasma population was magnetosheath-like in terms of ion concentration, ion energy distribution and electron energy distribution. The subsequent magnetopause crossing at $\sim 10: 22$ UT returned the spacecraft to a plasma environment that was generally magnetospherelike in nature until $\sim 10: 33 \mathrm{UT}$, when the spacecraft again crossed the magnetopause, exiting the magnetosphere for the last time on this pass.

As Cluster 1 approached the magnetopause for the first time, the observed magnetic field became increasingly variable in both direction and magnitude. This was particularly evident after $\sim 09: 00$ UT, when the (lagged) IMF turned southward at the subsolar point. It is, therefore, highly likely that the increased level of variability was directly linked to sustained dynamic processes in the boundary region. The most notable consequences of this are the four clear magnetospheric FTEs marked by the vertical dashed lines, observed at $\sim 09: 45$ UT, $\sim 09: 54$ UT, $\sim 09: 59$ UT, and $\sim$ 10:04 UT, prior to the entry into the boundary layer at $\sim 10: 09$ UT. These FTEs were characterised by bipolar positive-to-negative ("normal" polarity) perturbations in the normal component of the magnetic field $\left(B_{N}\right)$, and increases in the overall field strength. In addition, each FTE was accompanied by mixing of the magnetospheric and magnetosheath plasma populations. The exact nature of this mixing varied between the FTEs, although in general there was an increase in the ion concentration, particularly at magnetosheath-like energies $(\sim 100 \mathrm{eV}-5 \mathrm{keV})$ and, in some cases, a depletion of the more energetic magnetospheric ion population. Similar enhancements of magnetosheathlike plasma were observed in the electron measurements, although the depletion of the magnetospheric electron population was more pronounced than in the case of the ions, presumably reflecting the greater field-aligned mobility of the electrons.

Following the entry of Cluster 1 into the magnetosheath at 10:33 UT, further FTEs were observed with those at $\sim 10: 36$ UT, $\sim 10: 43$ UT, $\sim 10: 46$ UT, and $\sim 11: 01$ UT (marked by vertical dashed lines), being clear examples of FTE-like bipolar signatures in the magnetic field. These magnetosheath FTEs are also associated with mixing of magnetosheath and magnetospheric plasma, with the enhancement of magnetospheric electrons and ions being particularly prominent during the $\sim 10: 46$ UT event.

It is worth noting that analysis of the electron and ion observations now available reveals further evidence of ongoing dynamic processes at the high-latitude magnetopause that was not obvious when considering the magnetic field observations alone (as in Paper 1). From the outset of the interval shown in Fig. 3 (almost $1 \mathrm{~h}$ prior to the first magnetopause encounter), there are indications of brief intervals of magnetosheath-like ion and electron fluxes and depletion of the magnetospheric electron population at Cluster 1. The plasma observations also yield much additional structure associated with the magnetospheric and magnetosheath FTEs. In particular, it is possible to resolve short-lived enhancements in the magnetosheath-like ion and electron fluxes at $\sim 09: 51 \mathrm{UT}, \sim 09: 56 \mathrm{UT}, \sim 10: 02 \mathrm{UT}, \sim 10: 07 \mathrm{UT}$, and $\sim 10: 27$ UT. Once into the magnetosheath proper, additional enhancements in the magnetospheric-like ion and electron populations are apparent at $\sim 10: 50 \mathrm{UT}$ and $\sim 10: 52 \mathrm{UT}$. Whilst it is not within the scope of this paper to analyse each of these events in detail, it is clear that throughout the interval 09:15-11:15 UT on 14 February 2001, magnetic reconnection was occurring almost continuously at some locations on the dayside magnetopause, which resulted in FTEs being observed at the high-latitude post-noon boundary.

Our interpretation of the field perturbations observed during these FTE events is shown in Fig. 4a (we shall return to consider Fig. 4b later). This shows a schematic of the dayside magnetopause viewed from the Sun, where the arrowed dashed lines show undisturbed magnetospheric field lines in the magnetopause layer. Magnetic field lines interconnected with the IMF/magnetosheath are indicated by solid arrowed lines. We assume that the field perturbations observed by Cluster were due to bursts of reconnection occurring eastward and equatorward of the spacecraft (although, as dis- 
cussed below, we do not suggest that reconnection is occurring only in this region). In Fig. 4a reconnection is shown occurring at a point somewhere between the equator and the Cluster spacecraft, near the point marked ' 1 ' (the exact location is uncertain). Following reconnection, the combined action of the magnetosheath flow and the magnetic tension of the newly-opened field lines causes them to contract poleward and westward in the Northern Hemisphere, forming a sunward-moving boundary layer at the post-noon sector magnetopause, such as is described, for example, by the simple magnetopause reconnection model of Cowley and Owen (1989). At subsequent times the open field line (shown by the arrowed solid lines) is thus located at positions 2,3 , and 4 . It can thus be seen that the effect of the field tension is such as to cause newly-opened flux tubes at the Cluster location (near '2') to rotate towards a poleward and eastward orientation, in both the magnetosphere and magnetosheath. The westward and poleward propagation of newly-opened magnetic flux tubes perturb the underlying (closed) magnetospheric flux tubes in the vicinity of Cluster such as to give positiveto-negative bipolar perturbations in the $N$ component in both magnetosphere and magnetosheath (as presented in Fig. 4a of Wild et al., 2001). This scenario is thus qualitatively consistent with the sense of the principal FTE field perturbations seen in Fig. 3. The 'reversed' and reduced field tilting effects observed in the first three magnetospheric FTEs marked in the figure, compared with the fourth, is taken to be due to the larger distances from the magnetopause in the earlier events, combined with the twisting of the field within the FTE structure, as found in earlier studies of ISEE1/2 data (e.g. Cowley, 1982; Paschmann et al., 1982; Saunders et al., 1984). The FTE structure as a whole is formed from the bundle of open field lines produced by a given propagating burst of reconnection (Milan et al., 2000; Wild et al., 2001). The twisting is often such that in the outer part of the FTE the field may tilt away from the direction of the field on the other side of the boundary. Such tilts can also be produced in the unreconnected field immediately outside the FTE due to the flows induced in the surrounding medium by the passage of the FTE structure (Southwood, 1985; Cowley, 1986).

Whilst this interpretation of an active reconnection region located somewhere in the dusk sector equatorward of the Cluster spacecraft is consistent with the observations, it is not possible to say whether the reconnection $\mathrm{X}$-line lies on the equator or at higher or lower latitudes. Also, the Cluster data yields no information regarding the azimuthal extent of the reconnection region. For example, it is possible that reconnection is also occurring in the pre-noon sector, as indicated in Fig. 4b. Here, reconnection has been assumed to occur at some general location southward of the equatorial plane resulting in a similar evolution of newly-opened field lines to that described in the Northern Hemisphere case presented in Fig. 4a. Obviously, reconnected field lines with footprints in the Northern Hemisphere are dragged tailward (dawnward) by field line tension effects and the motion of the solar wind and consequently away from the Cluster spacecraft.
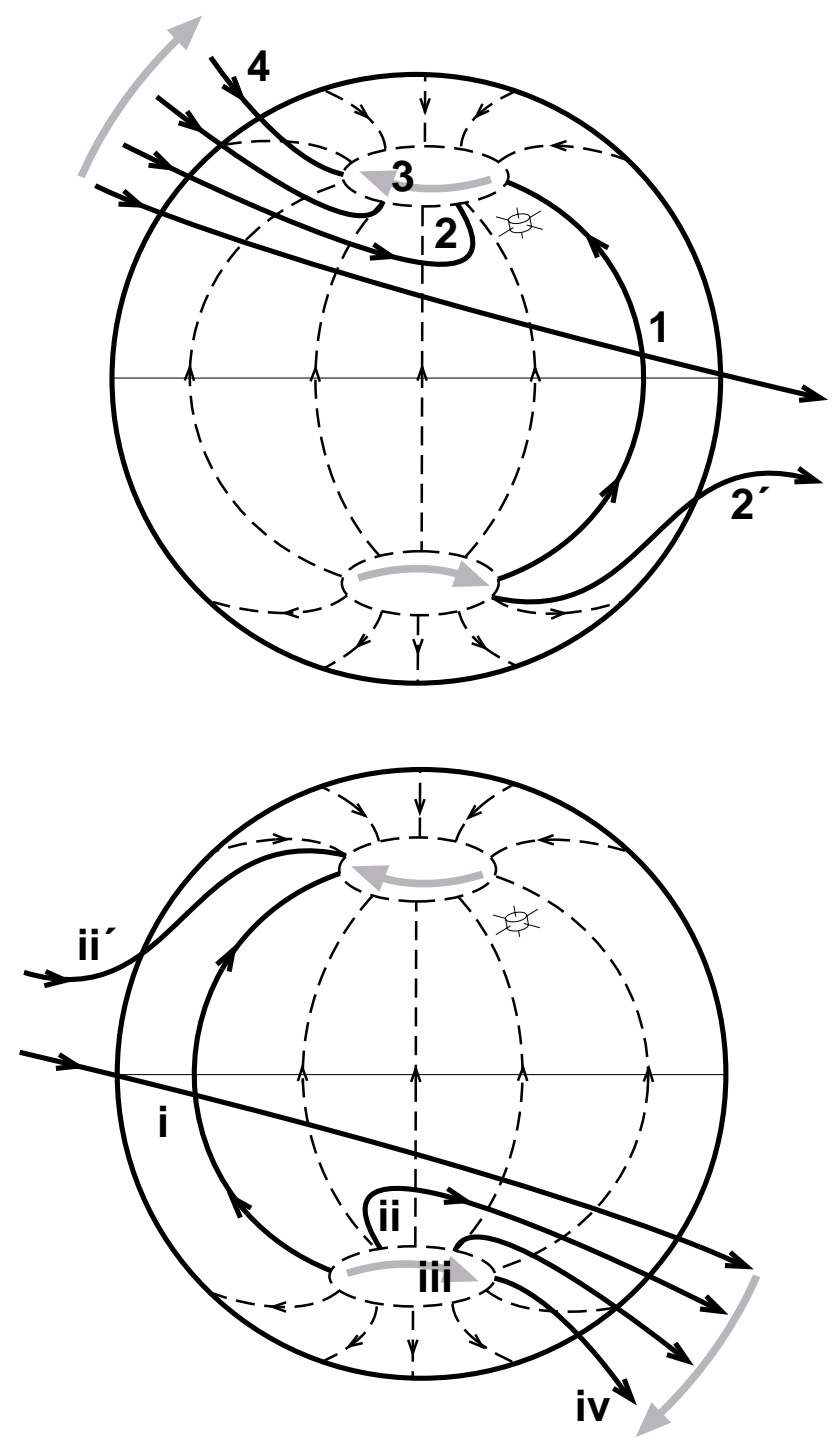

Fig. 4. Sketch of the Earth's dayside magnetopause in a view looking from the Sun, showing (a) the temporal evolution of an open flux tube (solid lines marked '1'-'4') following a low-latitude reconnection event in the dusk sector (near ' 1 ') and (b) the temporal evolution of an open flux tube (solid lines marked 'i'-'iv') following a low-latitude reconnection event in the dawn sector (near ' $i$ ') The grey arrows indicate the direction of open field line motion, including westward motion in the northern cusp and eastward motion in the southern cusp. The arrowed short-dashed lines indicate magnetospheric field lines within the magnetopause boundary region. We also indicate the approximate location of the Cluster spacecraft.

\subsection{SuperDARN radar observations}

Figure 5 presents observations of received backscattered power and l-o-s ionospheric Doppler velocity as functions of magnetic latitude and universal time from selected beams of the Finland (Fig. 5a) and Syowa East (Fig. 5b) SuperDARN radars. These plots indicate backscattered signals that originate from both ionospheric and ground scattering targets, colour coded according to the scales indicated. Through- 

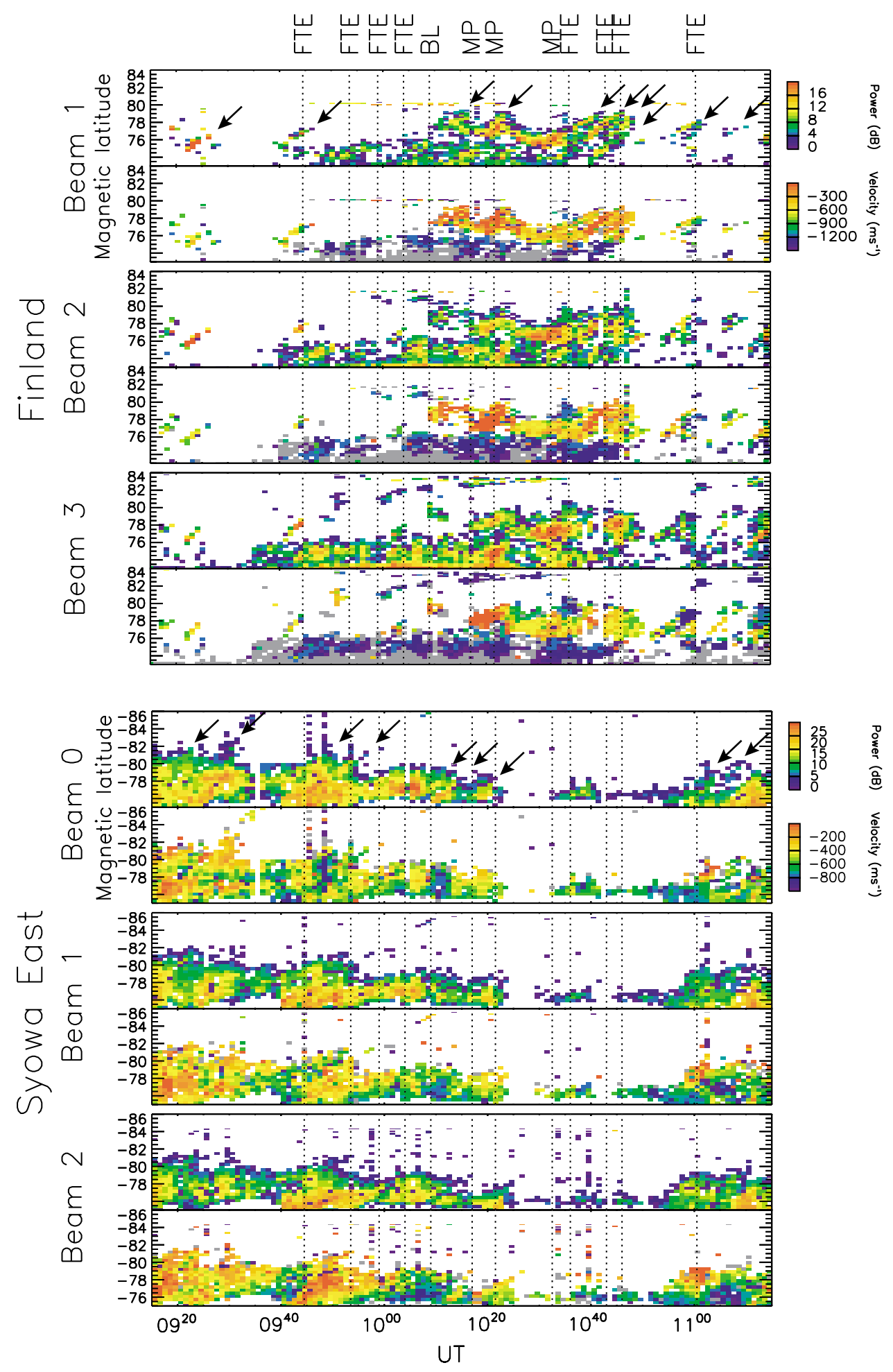

Fig. 5. Three pairs of backscatter power and Doppler shift measurements from (a) beams 1, 2, and 3 of the Finland radar and (b) beams 0 , 1, and 2 of the Syowa East radar, covering the same time interval as for the Cluster data in Fig. 3. In the Doppler shift panels, velocities are only shown where significant power is observed. Grey backscatter indicates ground backscatter, and negative velocities represent Doppler shifts away from the radar along the line-of-sight. Poleward-moving radar auroral forms (PMRAFs) are indicated by arrows in the upper power panel for each radar; related events are observed in each of the other beams shown. Superimposed on each panel are the times of note identified in the Cluster observations, as in Fig. 3. 
out the interval presented, the measured Doppler velocities at both the Finland and Syowa west radars were overwhelmingly negative (flow away from the radars). Consequently, the velocity colour scales are such that only negative Doppler shifts are shown; where signals have been identified as groundscatter (by exhibiting low Doppler velocity and narrow Doppler spectral width) the appropriate velocity data are colour-coded grey. Also, attention is drawn to the differences in the colour-scales (both power and velocity) between Figs. $5 a$ and b. This is necessary since the Syowa East radar generally observed stronger returned signals from lower velocity (less negative) flows than the Finland radar. For comparison, the timings of the key FTE and magnetopause encounters as discussed above and in Paper 1 are overlaid on each panel of Fig. 5.

Beginning with a summary of the Northern Hemisphere observations, first presented in Paper 1, the backscatter in the westernmost portion of the Finland radar f-o-v (i.e. the beams presented) was characterised by a region of groundscatter at magnetic latitudes equatorward of $\sim 76^{\circ}$, embedded in which were regions of ionospheric scatter. The 1-o-s Doppler velocity of this ionospheric scatter of $\leq 300 \mathrm{~m} \mathrm{~s}^{-1}$ away from the radar throughout. After approximately 10:10 UT, a region of ionospheric backscatter developed slightly poleward of this $\left(\sim 76^{\circ}-79^{\circ}\right)$ in which the 1-o-s Doppler velocity was significantly higher (more negative). As discussed in Paper 1, inspection of the 1-o-s velocity measurements in the region of the estimated footprint of the Cluster spacecraft did not reveal any significant pulsing of the ionospheric flow, probably because the fluctuations did not have a significant component in the 1-o-s direction (which was predominantly meridional) of the radar beam. It is the higher-latitude region of backscatter displayed in Fig. 5a that contains the clearest radar signatures of FTEs, indeed examples of both PMRAFs and PIFs are apparent during the interval. Two clear examples of PMRAFs (narrow regions of backscatter with negative Doppler velocity propagating $\sim 2^{\circ}$ poleward over a period of a few minutes) were observed at $\sim 09: 21$ UT and 09:41-09:45 UT in beams 1 to 3 of the Finland radar. During the interval 10:10-10:50 UT, several further events were observed that could be classified as both PMRAFs and PIFs; the backscatter poleward of $\sim 76^{\circ}$ latitude during this period was almost continuous but several poleward-moving enhancements in the backscattered power associated with elevated 1-o-s Doppler velocity were seen. These events are clearest in the backscattered power and Doppler velocity measurements from beam 1 and are marked by arrows in the upper panel of Fig. 5a. Finally, two further PMRAFs with similar characteristics to those seen at the beginning of the interval are observed at $\sim 10: 57$ UT and $\sim 11: 07$ UT, and these are also marked by arrows in Fig. $5 \mathrm{a}$.

Turning now to the newly available measurements from the Syowa East radar (Fig. 5b), it is immediately apparent that on this occasion the nature of the backscatter observed in the northern and southern conjugate ionospheres were markedly different. The Southern Hemisphere radar observed a region of backscatter in the most poleward point- ing beams of the f-o-v (beams $0-8$ ) extending from $\sim-75^{\circ}$ to $-78^{\circ}$ magnetic latitude. Unfortunately, this region of backscatter did not generally include the ionospheric footprint of the Cluster spacecraft, and the observations presented originate from $\sim 2^{\circ}$ poleward and $\sim 1-2 \mathrm{~h}$ MLT further west. In comparison to the Northern Hemisphere measurements the echoes received at the Syowa East radar were significantly stronger (higher received signal power), but were associated with generally smaller Doppler shifts. However, as in the Northern Hemisphere, the measured 1-o-s Doppler velocities were almost exclusively directed away from the radar (negative Doppler shifts). Of course, it must be remembered that the pointing direction of the Syowa East radar is quite different from the Finland radar; at $\sim 75^{\circ}$ magnetic latitude, the Finland radar beams presented in Fig. 5 (and shown in Fig. 1) point poleward and westward, whereas the Syowa beams (in the opposite hemisphere) point poleward and eastward. Consequently, the negative Doppler shifts observed by the Syowa East radar during this interval correspond to a poleward and eastward flow component in the Southern Hemisphere (compared to poleward and westward flow component observed by the Finland radar in the Northern Hemisphere). Also, the presented beams of the Syowa East radar are more azimuthally pointing than those of the Finland radar and are, therefore, more sensitive to the zonal component of the ionospheric flow. In further contrast to the Northern Hemisphere observations, the flow within the backscatter is broadly similar over the latitude range presented (that is to say that the two bands of backscatter observed in the Northern Hemisphere, each with substantially different flow characteristics were not matched in the Southern Hemisphere). Embedded within and extending from the region of Southern Hemisphere backscatter were several examples of PMRAFs/PIFs (indicated by arrows in the power panel for beam 0). Due to the generally lower Doppler velocities observed in the Southern Hemisphere (compared to those in the higher latitude band of scatter in the Northern Hemisphere) the subtle differences between the velocity within the poleward moving structure and the surrounding backscatter are not always obvious, although the PMRAFs are apparent, extending from the poleward edge of the scatter at 09:20-09:22 UT, 09:26-09:32 UT, 09:53-09:57 UT, 11:02-11:05 UT, and 11:06-11:10 UT.

In Paper 1, Wild and co-workers demonstrated a pulsing of the flow in the lower latitude band of scatter observed in the Northern Hemisphere. This pulsing was in addition to the PMRAF/PIFS observed at higher latitudes and in the band of scatter that corresponded to the approximate latitude of the Cluster footprint, albeit some $2 \mathrm{~h}$ of MLT westward. Figure 6a presents evidence of such pulsing, drawn from beam 3 of the Finland radar (this beam was chosen as it has the longest unbroken series of measurements in the lower latitude backscatter region). In order to highlight the 1-o-s velocity fluctuations in the lower latitude band of radar backscatter, a colour scale with a reduced velocity range compared to that in Fig. 5a has been employed. Using this modified colour scale, the poleward-propagating organisation of 

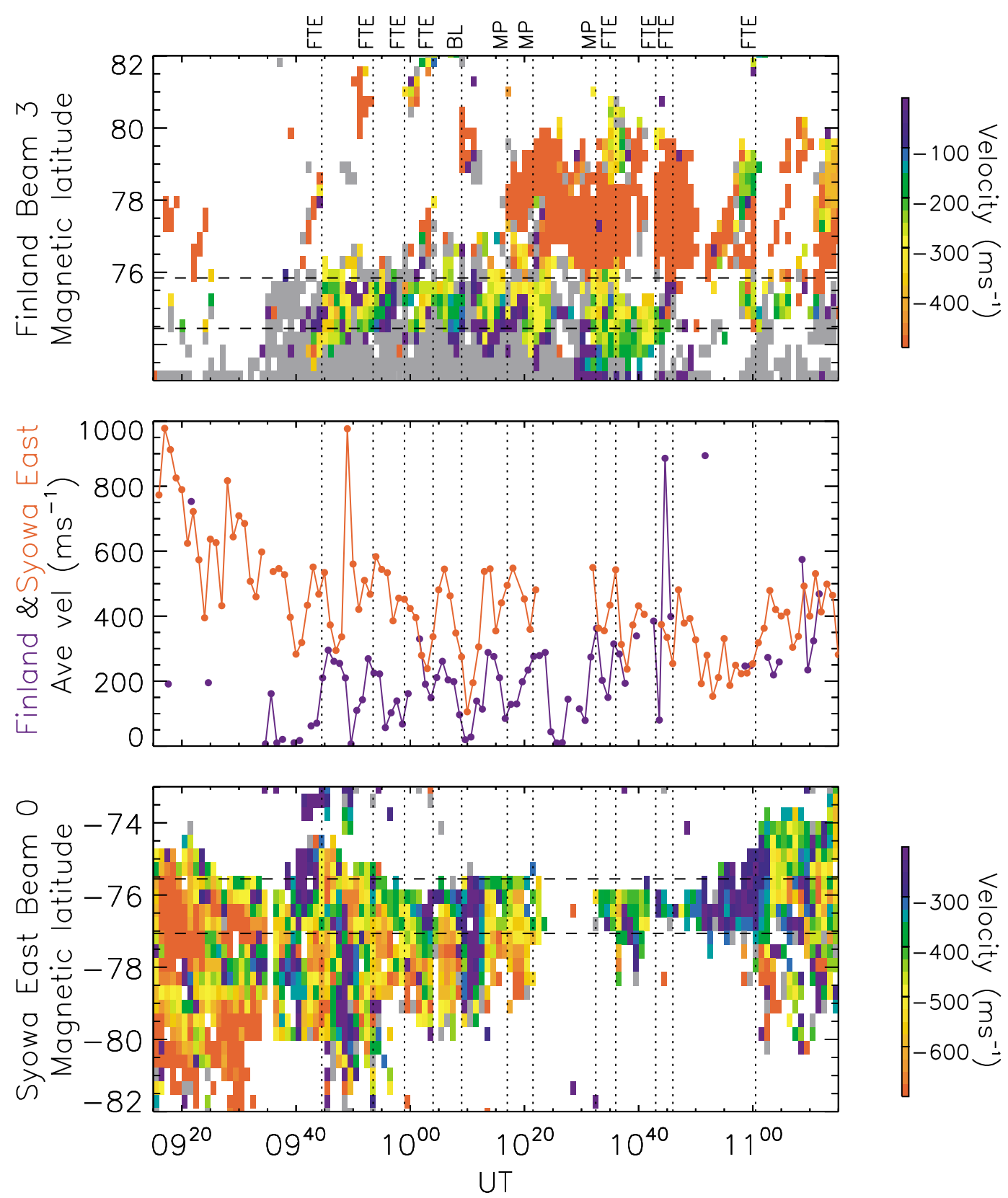

Fig. 6. (a) Velocity data from beam 3 of the Finland radar, in a format similar to that in Fig. 5, but with a revised colour scale which reveals the pulsing of the line-of-sight flow in the band of lower-latitude scatter. (c) Velocity data from beam 0 of the Syowa East radar, presented in the format of (a), albeit with a different colour scale and a reversed latitude axis. (b) The mean velocity averaged over the latitude range indicated by dashed horizontal lines in (a) and (c) (and given positive values in this case, though in each case the flow is directed away from the radars). The indigo trace corresponds to the Finland average velocities, whilst the red trace corresponds to the Syowa East average velocities. Superimposed on each panel are the times of note identified in the Cluster observations, as in Fig. 3.

the velocity features in the latitude range $\sim 74.5^{\circ}-76.0^{\circ} \mathrm{N}$ is clear. In order to further emphasise the velocity pulsations, the average 1-o-s Doppler speed between these latitudes (indicated by dashed lines) is presented in Fig. 6b. This displays the average flow speed measured in the direction away from the Finland radar (i.e. negative velocities), as indigo circles joined by indigo lines. As reported in Paper 1, the enhancements in the average Doppler velocity measured by the Finland radar occurred in association with each of the four magnetospheric FTEs, with peak values occurring typically 1-2 min after what had been judged to be the "centre" time of the FTEs inferred from Cluster magnetic field data (indicated by dashed lines in Fig. 6). Of course, depending upon the relative propagation times from the reconnection site over the magnetopause to the spacecraft, along the magnetic field to the ionosphere, and from then on to the radar 
field-of-view, the relative timing of such pulses for individual events will vary slightly. It is expected that these propagation times will typically be $\sim 1-5 \mathrm{~min}$, therefore, $\sim 1-2$ min displacements in either direction are not unexpected, depending upon the various factors influencing the propagation delay in each case. This interpretation is supported by the Cluster plasma observations now available, indeed additional FTElike events identified from the electron and ion observations discussed above can be related to additional variations in the Finland radar flow observations and may further explain the smaller velocity enhancements between the peaks associated with each of the marked FTEs.

It is worthwhile to compare the average ionospheric flow velocity at the approximate magnetic latitude of the Cluster footprint in the Northern Hemisphere with those at equivalent latitudes in the Southern Hemisphere. The red circles and lines in Fig. $6 \mathrm{~b}$ indicate the corresponding average flow speed measured in the direction away from beam 0 of the Syowa East radar over the latitude range $\sim 74.5^{\circ}-76.0^{\circ} \mathrm{S}$. These data are drawn from the 1-o-s Doppler velocity measurements presented in Fig. 6c (and shown in Fig. 5b but with differing velocity and latitude scales). It is immediately apparent that the average flow velocity in the Southern Hemisphere consists of similar velocity fluctuations to those observed in the Northern Hemisphere (typically $\sim 200-300 \mathrm{~m} \mathrm{~s}^{-1}$ variations with $\sim 5-10$ min periodicity) but superimposed upon a background flow of $\sim 300 \mathrm{~m} \mathrm{~s}^{-1}$. Note also that at the beginning of the interval presented the Southern Hemisphere radar observed sustained backscatter with flow $=1000 \mathrm{~m} \mathrm{~s}^{-1}$ directed away from the radar, whilst in the Northern Hemisphere scattering targets were not present. By the end of the interval, the average flow velocity over the $\sim 74.5^{\circ}-76.0^{\circ}$ latitude range in both hemispheres had converged to approximately $400 \mathrm{~m} \mathrm{~s}^{-1}\left( \pm 200 \mathrm{~m} \mathrm{~s}^{-1}\right)$.

The Northern Hemisphere observations suggest a relationship between the FTE signatures observed by Cluster at the high-latitude post-noon magnetopause and enhancements in 1-o-s Doppler velocity and power observed in the backscatter echoes. In particular, these enhancements are observed in the lower latitude $\left(\sim 74.5^{\circ}-76.0^{\circ} \mathrm{N}\right)$ westward flow region. As indicated in Fig. 4a, this westward flow is consistent with the expected motion of recently connected magnetic flux tubes as they are dragged dawnward and poleward, first by magnetic tension effects acting on the kinked field lines, and then by the antisunward motion of the solar wind. It is especially interesting that there is such excellent correspondence between the ground- and space-based observations, despite the measurements of ionospheric flow being made $\sim 2 \mathrm{~h}$ of MLT to the west of the Cluster footprint. It is unfortunate that similar observations could not be made in closer proximity to the Cluster footprint. However, as discussed above, the radar look-direction in the ionosphere directly conjugate to the spacecraft was approximately north-south and, therefore, insensitive to the westward flow variations, and it is expected that the events and associated ground-based signatures under study are large in spatial scale. The observation of ionospheric flow modulations some $2 \mathrm{~h}$ of MLT westward of the Cluster footprint in the Northern Hemisphere ionosphere adds further weight to this supposition. In Paper 1, Wild et al. noted that some ground-based events were observed without a clear FTE signature at the Cluster spacecraft, such as the Northern Hemisphere PMRAFs observed at $\sim 09: 21$ UT and $\sim 09: 41$ UT. It was proposed that this was due to the greater displacement of the spacecraft from the magnetopause at the beginning of the interval, with each spacecraft simply too far away from the boundary to observed the related FTE signatures. With the benefit of plasma measurements it can be seen that this interpretation (based upon magnetic field measurements alone) is supported by observations of weak enhancements of magnetosheath-like ion and electron fluxes during the period prior to the FTE observed at $\sim 09: 45$ UT. Indeed, the $\sim 09: 21$ UT PMRAF coincided with a clear burst of magnetosheath-like ions, a region of elevated magnetosheath-like and depleted magnetospheric electron fluxes, and bipolar fluctuations in the normal component of the magnetic field. Very brief $(\sim 30 \mathrm{~s})$ bursts of magnetosheath-like electron fluxes were also observed around the time of the $\sim 09: 41$ UT PMRAF, although it is difficult to resolve distinct enhancements in the ion population associated with these features.

The Cluster magnetic field observations and the Northern Hemisphere measurements of ionospheric flow presented in Paper 1 were interpreted as consistent with a propagating burst of low-latitude reconnection that originated near the noon meridian and then propagated to later local times. Once the reconnection patch had propagated sufficiently duskward of the Cluster spacecraft, the dawnward motion of newlyopened flux tubes gave rise to the field-tilting effects apparent in the in situ magnetic field measurements and the propagating transient features in the ground-based measurements of ionospheric flow. Although it was acknowledged that such a propagating burst of reconnection could also propagate toward earlier local times, no observations were available to determine whether or not this was actually the case on this occasion.

In order to further elucidate the large-scale ionospheric flow pattern, the perturbations of which have been presented above, we shall employ the "map potential" technique developed by Ruohoniemi and Baker (1998). This technique yields large-scale global convection maps from the l-o-s velocity measurements from multiple radars, via mathematical fitting of the data to an expansion of the electrostatic potential in spherical harmonics. First, the 1-o-s data are filtered and then mapped onto a polar grid. These "gridded" measurements are then used to determine a solution for the electrostatic potential distribution that is most consistent with the available measurements. The electric potentials of the solution then represent the plasma streamlines of the modelled convection pattern. As backscatter targets (and therefore 1-o-s velocity measurements) are not always available, information from the statistical model of Ruohoniemi and Greenwald (1996), parameterised by IMF conditions, is used to stabilise the solution where no measurements are made. Figure 7 presents the dayside Northern and Southern Hemi- 


\section{FEBRUARY 2001 \\ 09:40:00 - 09:45:00 UT NORTHERN HEMISPHERE}

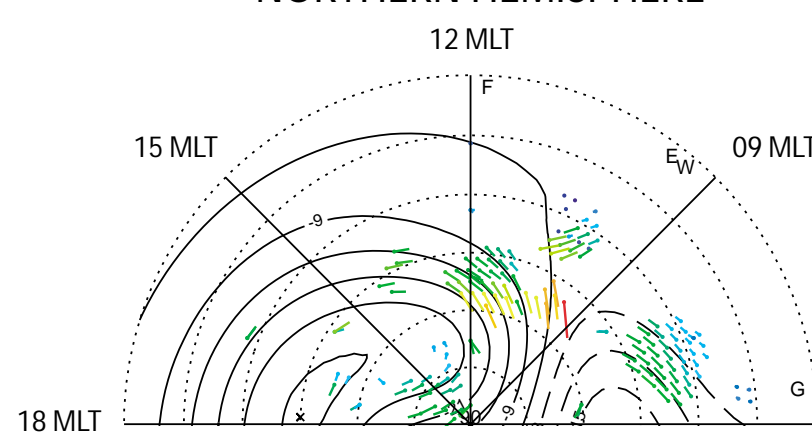

SOUTHERN HEMISPHERE

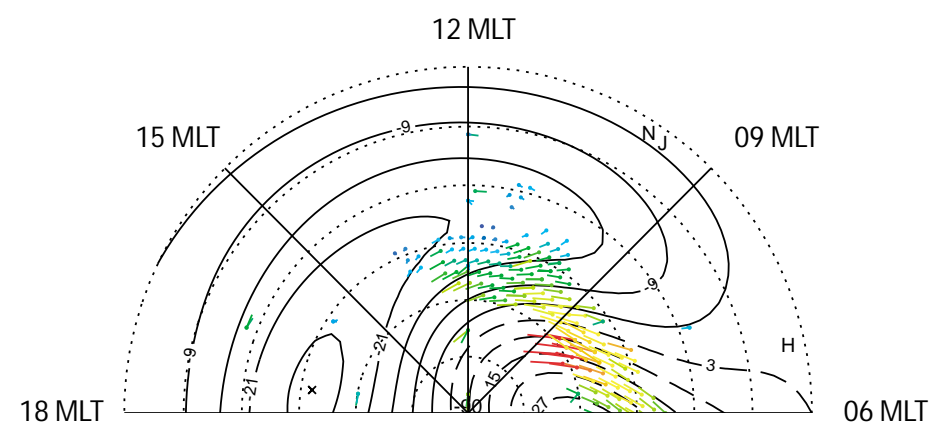

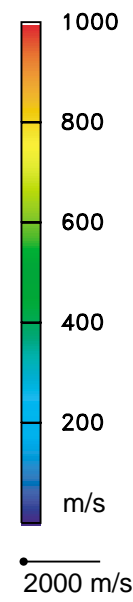

APL MODEL

$4<\mathrm{BT}<6$

$\mathrm{Bz}-/ \mathrm{By}+$

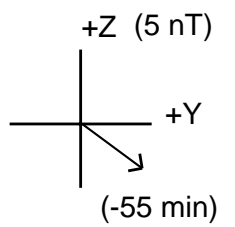

Fig. 7. Streamlines and vectors of the ionospheric flow derived from SuperDARN velocity measurements in the dayside Northern (upper panel) and Southern (lower panel) Hemisphere ionosphere, obtained from the "map-potential" technique described in the text. Solid (dashed) black lines represent streamlines corresponding to negative (positive) equipotential contours. The data are presented on a geomagnetic grid with lines of constant magnetic latitude at $5^{\circ}$ increments indicated by the dotted concentric circles. Magnetic local time meridians are represented by solid lines at 06, 09, 12, 15, and 18 MLT. The velocity vectors are scaled and colour-coded to indicate flow speed as described in the key to the right. In addition, in the lower right corner we indicate the flow model employed to stabilize the potential solution in regions where no data are available, obtained from the statistical study of Ruohoniemi and Greenwald (1996).

sphere ionospheric convection patterns, each averaged over the period 09:40-09:45 UT on 14 February 2001. Dotted concentric semi-circles indicate lines of constant magnetic latitude in $5^{\circ}$ increments whilst local noon is located at the top of each plot with dawn on the right-hand side and dusk on the left, as if the observer were looking down from a location above the northern magnetic pole. Note that for consistency, the same arrangement has been used for the Southern Hemisphere. The temporal averaging $(\sim 5 \mathrm{~min})$ is necessary in this case, as there were generally insufficient l-o-s data in each individual scan $(\sim 1 \mathrm{~min})$ to satisfactorily constrain the solution for the electrostatic potential. Although this technique is equally applicable to both the Northern and Southern Hemispheres, the Ruohoniemi and Greenwald (1996) statistical model is based upon measurements from the Northern Hemisphere Goose Bay radar only. As no equivalent statistical model of the large-scale Southern Hemisphere ionospheric convection pattern is currently available, the Northern Hemisphere model is employed but with the IMF $B_{Y}$ selection parameter reversed, i.e. it is assumed that the iono- spheric convection pattern is approximately anti-symmetrical in opposite hemispheres, due to the differing consequences of a non-zero dawn-dusk component of the IMF. For example, during the interval presented, the (lagged) IMF conditions relevant to the parameterisation of the statistical model were IMF $B_{Y}+$ ve, $B_{Z}$ - ve with the field strength $\sim 5 \mathrm{nT}$, as indicated in the lower right-hand corner of Fig. 7. Consequently, the Ruohoniemi and Greenwald (1996) Northern Hemisphere convection pattern for $4 \mathrm{nT}<\left|\mathrm{B}_{\mathrm{IMF}}\right|<6 \mathrm{nT}$ with $B_{Y}+$ and $B_{Z}$ - was employed to stabilise the Northern Hemisphere fit, whereas the $4 \mathrm{nT}<\left|\mathrm{B}_{\mathrm{IMF}}\right|<6 \mathrm{nT}$ with $B_{Y}$ and $B_{Z}$ - statistical convection pattern was used to stabilise the Southern Hemisphere solution. In this study, spherical harmonic fits which use terms up to the fourth power are employed to fit the data from eight Northern Hemisphere and four Southern Hemisphere SuperDARN radars. The locations of the radars on the dayside (i.e. those appearing in Fig. 7) at the time of the plot are indicated by alphabetical identifiers, these being Finland (F), Iceland East (E), Iceland West (W) and Goose Bay (G) in the Northern Hemi- 
sphere and Syowa East (N), Syowa South (J) and Halley Bay $(\mathrm{H})$ in the Southern Hemisphere (the other radars being located on the nightside at this time). The solid (dashed) black lines represent the negative (positive) equipotential contours, and therefore, the ionospheric plasma flow streamlines, determined from the map potential algorithm. The coloured dots indicate locations where radar 1-o-s velocity data are available. The vectors drawn from these dots, sometimes referred to as "true vectors", are calculated by combining the measured 1-o-s velocity and the component of the convection flow (from the fitted solution) that is orthogonal to the 1-o$\mathrm{s}$ direction (i.e. the radar beam) at each location. Both the vectors and the dots are colour coded according to the true vector's velocity magnitude, as indicated by the colour scale on the right-hand side of the figure; the length of the vector also indicates the magnitude of the velocity at that location, the scale is shown on the right-hand side of the figure. In general, the true vectors in Fig. 7 are approximately aligned with the derived flow streamlines, suggesting that in most cases, the solution is a good fit to the 1-o-s velocity data available. Unfortunately, by averaging over a 5-min period, short duration velocity fluctuations, such as those presented in Fig. 5, are effectively smoothed out, and it is chiefly for this reason that only two representative convection maps are presented here. In any case, the map potential technique is not intended to accurately image small-scale features in the global convection pattern and given the limited backscatter observed during the interval presented, it would perhaps be unwise to over-interpret the results. Nevertheless, the Northern and Southern Hemisphere convection patterns presented in Fig. 7 clearly illustrate the large-scale ionospheric flow observed by the radars during this interval, and onto which the smallscale flow disturbances discussed above are superimposed. In the map corresponding to the Northern Hemisphere, the noon sector ionospheric flow between $\sim 75^{\circ}-80^{\circ} \mathrm{N}$ MLAT is predominantly westward, with ionospheric plasma moving along streamlines from later to earlier local times and turning antisunward (as indicated by stronger poleward velocity components in the western portion of the Finland radar f-ov) as the flow diverts into the polar cap in pre-noon sector. The flows measured by the Goose Bay radar are consistent with this configuration with predominantly sunward flows being observed at lower latitudes in the dawn sector. This flow pattern is in contrast to that inferred from the Southern Hemisphere data; as shown in the Syowa East 1-o-s velocity measurements presented in Figs. 5 and 6, the ionospheric flow in the noon sector between $\sim 75^{\circ}-80^{\circ} \mathrm{S}$ MLAT is almost exclusively eastward with ionospheric plasma moving from earlier to later local times before diverting into the polar cap. More extensive backscatter in the Southern Hemisphere polar cap at this time has allowed the throat of the high-latitude convection pattern to be imaged with some confidence. In comparison to the Northern Hemisphere where the flow into and across the polar cap appears to be directed almost antisunward at $\sim 11$ MLT, the Southern Hemisphere flow had a much larger duskward component at this location. However, it is interesting to note, despite the limited backscatter available, the remarkable consistency of the flow patterns presented with the inferences regarding the motion of newly-reconnected field line footprints based upon lineof-sight data alone and the theoretical predictions of expected flow patterns based upon IMF conditions (Cowley and Lockwood, 1992). The estimated pre-noon location of the throat of the convection pattern in both the Northern and Southern Hemispheres is, at least in part, a consequence of the Ruohoniemi and Greenwald (1996) statistical model of ionospheric convection employed by the map potential technique to stabilise the solution where no 1-o-s data are available. This model, based upon six years of observations from the Goose Bay SuperDARN radar, suggests that the throat of the Northern Hemisphere high-latitude ionospheric convection pattern is located in the pre-noon sector regardless of whether the IMF has either a duskward or dawnward component. Consequently, the selection of the appropriate statistical model for the Southern Hemisphere, corresponding to the reverse of the observed IMF $B_{Y}$ component, is not expected to shift the convection Southern Hemisphere throat into the post-noon sector. Of course, irrespective of the chosen statistical model, the estimated convection flow in the regions containing ionospheric scatter is influenced primarily by l-o-s velocity data, as is the case in the vicinity of the Northern and Southern Hemisphere convection throats presented here. The asymmetric location of the convection throat in the pre-noon sector for both positive and negative $B_{Y}$ conditions has been reported previously. For example, Moses et al. (1987) presented a time dependent model of ionospheric flow patterns that incorporated a realistic day-night ionospheric conductivity gradient. Once this conductivity variation was taken into account, mirror symmetry between positive and negative IMF $B_{Y}$ convection patterns was destroyed, and the model reproduced the main features of ion flow observations made by spacecraft over the polar cap (e.g. Heelis, 1984; Burch et al., 1985). Furthermore, although the convection throat is located slightly dawnward of noon in both the Northern and Southern Hemisphere convection patterns presented in Fig. 7, the asymmetry of the plasma motion into the throat in the $\sim 11: 00$ MLT sector is quite apparent (being predominantly dawnward in the Northern Hemisphere and duskward in Southern Hemisphere). This suggests that in each hemisphere the region of the ionosphere that maps to the reconnection location on the magnetopause, the so-called "merging gap", is extended in azimuth and not limited to the relatively narrow convection throat. Consequently, Fig. 7 hints at the extended (or multiple) nature of the reconnection site (or sites) necessary to produce the observed pulsations in the ionospheric flow velocity and PIFs/PMRAFs observed at higher latitudes in both hemispheres. Given that the observations presented above are consistent with the dusk-dawn propagation of newly-reconnected flux tubes over the Cluster spacecraft in the Northern Hemisphere post-noon sector, it is to be expected that radar observations of the Northern Hemisphere noon sector ionosphere will indicate enhancements in the dawnward and poleward flow. The plasma streamlines in the Northern Hemisphere convection map sug- 


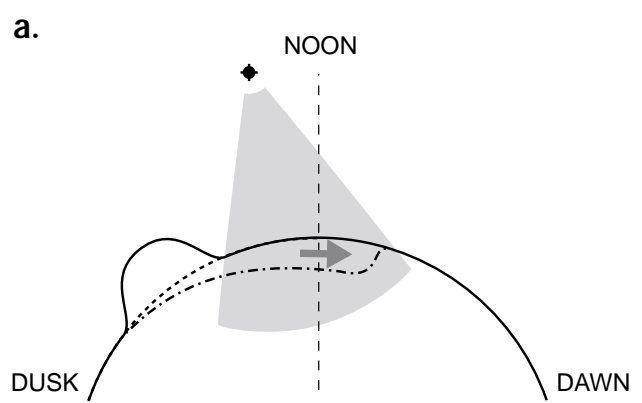

NORTHERN HEMISPHERE

c.

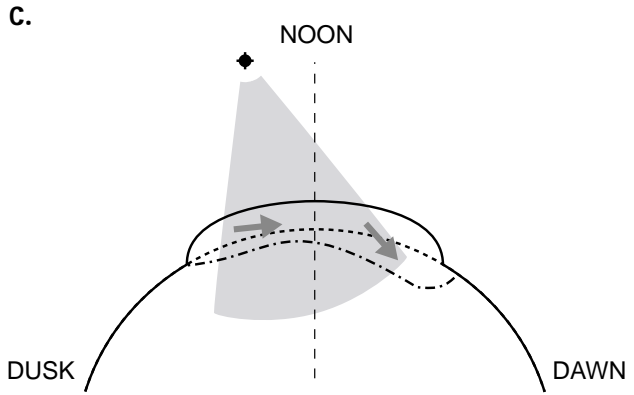

NORTHERN HEMISPHERE

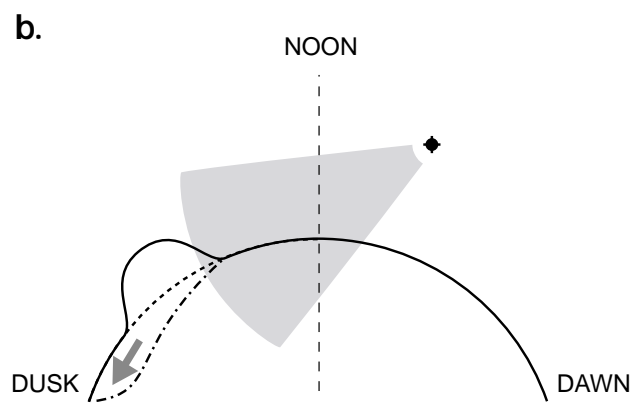

SOUTHERN HEMISPHERE

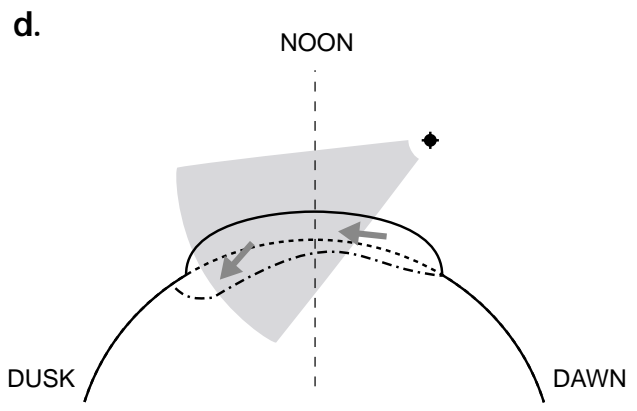

SOUTHERN HEMISPHERE

Fig. 8. Schematic indicating the expected perturbations to the ionospheric open-closed field line boundary (OCFLB) and the resulting ionospheric flows due to the addition of open flux during a flux transfer event. In each figure, the view is from a location above the northern magnetic pole, with the noon meridian indicated by a long dashed line and dawn (dusk) located to the right (left) of the plot. In each case the OCFLB is represented by a solid black line. The field-of-view of the Finland (Syowa East) radar is indicated in the Northern (Southern) Hemisphere by the grey shaded region at approximately 10:00 UT. Where a perturbation (i.e. a region of newly-opened flux tubes appended to the OCFLB) is shown, the quasi-equilibrium position of the boundary is indicated by a short dashed line. Following integration into the (open) polar cap, the region of newly-opened flux is indicated by a dot-dashed line whilst the ionospheric flow that brings about the inclusion of this region into the polar cap is indicated by a shaded arrow. The expected Northern and Southern Hemisphere responses to the addition of open flux in the post-noon sector are shown in (a) and (b) respectively. Similarly, the expected Northern and Southern Hemisphere responses to the addition of a spatially extended region open flux that straddles noon are shown in (c) and (d).

gest the direct motion of the footprints of newly-opened flux tubes from the vicinity of Cluster ( 14:00 MLT) toward the Finland radar f-o-v. However, this is most certainly not the case in the Southern Hemisphere. In order to pass in an easterly (duskward) direction through the Syowa East f-o-v (also located in the noon sector), the newly-opened flux tubes must originate from a location significantly westward (dawnward). Clearly, the flow perturbations and transient features observed by these two radars are the result of either an X-line extended over many hours of local time (at least four) or multiple reconnection sites separated in azimuth by a similar displacement.

Referring once again to Fig. 4, it is clear that low-latitude reconnection limited to a region duskward of the Cluster spacecraft (near to 1 in Fig. 4a) would not result in the ionospheric disturbances observed close to noon in both hemispheres during this interval. Once reconnection had occurred, newly-opened flux tubes in the Southern Hemisphere would be dragged duskward and antisunward (away from noon as indicated by 2' in Fig. 4). This is illustrated schematically in Figs. 8a and 8b. Figure 8a presents a view of the day- side portion of the open-closed field line boundary (OCFLB) in the high-latitude Northern Hemisphere ionosphere looking down from a location above the North Pole. The OCFLB itself is indicated by a solid black line, whilst the f-o-v of the Finland radar is represented by the grey shaded area. In Fig. 8a, a bundle of recently opened magnetic flux tubes have been appended to the equatorward edge of the OCFLB due to a spatially limited burst of reconnection somewhere in the post-noon sector. This has lead to a bulge in the boundary away from its quasi-equilibrium position in the post-noon sector, as indicated by the dashed line. Over time, this region of newly-opened flux is integrated into the polar cap (indicated by the region bounded by the dot-dashed line) as the newly-opened flux tubes are dragged dawnward and poleward, by field tension effects acting on the kinked field lines, and then by the antisunward motion of the solar wind (indicated by the arrow). The resulting ionospheric flow is, therefore, directed westward (dawnward) and poleward across the f-o-v of the Finland radar, consistent with the observations presented above. Figure 8b presents the corresponding scenario in the Southern Hemisphere ionosphere. Clearly the 
duskward and antisunward motion of the bundle of newlyopened flux tubes as they are integrated into the open polar cap region will result in the excitation of ionospheric flows that are outside of, and directed away from, the f-o-v of the Syowa East radar.

Consequently, if the magnetospheric and ionospheric signatures of FTEs observed during this interval are the consequences of a burst of low-latitude reconnection, the Southern Hemisphere ionospheric flow disturbances must be in response to FTEs originating dawnward of the noon meridian and propagating duskward (as indicated in Fig. 4b). Certainly, the observations presented indicate that during this interval, reconnection is not limited to a single, spatially localised region.

Moreover, the reconnection processes responsible for the magnetospheric and ionospheric dynamics observed during the interval under scrutiny must be either multiple in nature or sufficiently extended so as to initiate FTE signatures over many ( 4) hours of MLT. Whether or not multiple reconnection sites are a consequence of the propagation of the reconnection region wave-like over the magnetopause is difficult to determine from the data presented above, although the observations in this case can be interpreted as consistent with a reconnection site propagating away from noon. However, a one-to-one correspondence between the pulsations in the ionospheric flow at the approximate latitude of the Cluster footprint in each hemisphere would suggest (i) a single reconnection region that drives ionospheric flow bursts in both hemispheres almost simultaneously and (ii) that this reconnection region must extend over many hours of local time, in order to drive noon-sector ionospheric flows that are oppositely directed (in azimuth at least) in each hemisphere. Returning to Fig. 6, the correspondence between the average 1-o-s flow velocity measured in the Northern and Southern Hemispheres is quite remarkable, especially between $\sim 09: 40-10: 20$ UT. Although there are insufficient data to perform a rigorous cross-correlation analysis of this apparent correspondence, and despite an offset of $\sim 300 \mathrm{~m} \mathrm{~s}^{-1}$, it is clear that between $\sim 09: 40-10: 00 \mathrm{UT}$, the velocity variations in the Southern Hemisphere lead those in the Northern Hemisphere by $\sim 2-3 \mathrm{~min}$. Further correspondence can be seen in the interval 10:00-10:20 UT, although the lag between the pulsations in each hemisphere appears greatly reduced. Certainly, it is possible to identify similarities between the two average velocity profiles, albeit with a variable interhemispheric lag. Such small interhemispheric differences are to be expected if the reconnection region driving the ionospheric flows is significantly extended in local time, especially considering the significant IMF $B_{Y}$ component prevailing during this interval.

Reconnection over a wide range of local times can be envisaged as a combination of the field line evolution presented in Figs. 4a and b, whilst the ionospheric response to such a spatially extended reconnection site is presented schematically in Figs. 8c and d. The scenario indicated in Fig. 8c is similar to that in Fig. 8a, except that the reconnection region straddles noon, extending over $\sim 4 \mathrm{~h}$ of local time. This re- connection region has resulted in a bulge in the pre- and postnoon sectors of the Northern Hemisphere OCFLB which, for the reasons stated above, will be dragged dawnward and poleward across the quasi-equilibrium OCFLB. It is expected that the motion of the ionospheric footprint of these flux tubes would not significantly alter the expected ionospheric flow within the f-o-v of Finland radar compared to the expected dawnward and poleward flows that would be excited by a spatially limited reconnection region in the afternoon sector (Fig. 8a). However, a reconnection site that extends into the pre-noon sector will significantly alter the expected flow in the Syowa East radar located in the Southern Hemisphere, as indicated in Fig. 8d. The duskward and poleward motion of the footprint of newly-opened flux tubes is directed into the f-o-v of the Syowa East radar where observations of eastward and poleward flow are, therefore, expected. In other words, whilst the simultaneous observation of FTEs in the high-latitude post-noon magnetopause (from Cluster) and pulsed westward (dawnward) flow in the Northern Hemisphere noon-sector ionosphere (from the SuperDARN Finland radar) presented by Wild et al. (2001) were consistent with either of the scenarios presented in Fig. 8a or Fig. 8c, the observations of pulsed eastward (duskward) flow in the Southern Hemisphere noon-sector ionosphere (from the SuperDARN Syowa East radar) are consistent with Fig. 8d, but not Fig. 8b. Thereforewe must conclude that during this interval, a sustained interval of pulsed magnetic reconnection was occurring simultaneously in both the pre- and post-noon sectors. Furthermore, the correspondence between the flow modulations in the Northern and Southern Hemisphere ionospheres presented above suggest that reconnection was occurring in a single spatially extended region spanning at least $4 \mathrm{~h}$ of local time.

\section{Summary}

In this paper we have extended the work of Wild et al. (2001) in order to compare the ionospheric flow response in both the Northern and Southern Hemisphere ionospheres during an interval in which the Cluster spacecraft, located in the vicinity of the high-latitude post-noon magnetopause, observed a series of FTEs. These FTEs were characterised by several long-period (a few minutes) magnetic disturbances and the mixing of magnetosphere- and magnetosheath-like plasmas. The magnetospheric FTEs were observed close to the location of, and are similar in form to the original "flux erosion events" observed in HEOS2 data by Haerendel et al. (1978). As demonstrated by Wild et al. (2001), the field perturbations observed in these events, both in terms of the sense of the bipolar signatures in the field component normal to the magnetopause, and of the field shears observed in the plane of the magnetopause, are consistent with the observation of open flux tubes connected to the Northern Hemisphere ionosphere which were formed by pulsed reconnection at the post-noon magnetopause. 
High frequency coherent-scatter radar observations of the Northern Hemisphere ionospheric flow in the noon sector at the magnetic latitude of the Cluster footprint indicate a band of backscatter which corresponds to the cusp ionosphere located just poleward of the open-closed field line boundary. The flow within this region of backscatter is predominantly westward and poleward, consistent with the $B_{Y}$ positive IMF conditions at the time. The line-of-sight Doppler velocity and backscattered power within this region of backscatter, as measured by the SuperDARN Finland radar, was observed to pulse in close synchronization with the FTEs observed by Cluster. Furthermore, the flow and power pulses were observed propagating poleward within the radar's field-ofview, forming classic "pulsed ionospheric flow" and "poleward moving radar auroral form" signatures. Measurement from the Syowa East radar which is located in the Southern Hemisphere conjugate to the Finland radar indicate that the ionospheric flow is directed eastward and poleward, once again consistent with the prevailing $B_{Y}$ positive IMF conditions. The Southern Hemisphere observations also indicate a pulsing of the flow and backscattered power at the approximate latitude of the Cluster footprint and PIF/PMRAF signatures at higher magnetic latitude. Furthermore, there appears to be a good correspondence with the features observed in the Northern Hemisphere ionosphere during part of the interval presented.

Whilst it is clear that both Northern and Southern Hemisphere radars are observing the classic ionospheric signatures of FTEs, only the Northern Hemisphere observations correspond to the in situ observations of FTEs made by the Cluster spacecraft. Following reconnection, flux tubes whose footprint remains in the Northern Hemisphere will be dragged westward and poleward via the combination of magnetic field tension and the antisunward motion of solar wind. This motion results in the ionospheric footprint of post-noon sector flux tubes being dragged through the field-of-view of the SuperDARN Finland radar. Asymmetry due to positive $B_{Y}$ component of the IMF causes the Southern Hemisphere portion of recently-reconnected flux tubes to propagate eastward and poleward. Consequently, the Southern Hemisphere footprints of flux tubes reconnected in the post-noon sector will propagate eastward and away from the field-of-view of the Syowa East radar located in the noon sector. In order to observe the ionospheric signatures of newly-opened flux tubes propagating eastward and poleward in the field-of-view of the Syowa East radar, there must exist a reconnection site in the pre-noon sector. Therefore, we conclude that during the interval presented, the active reconnection region must be sufficiently extended in local time (at least $\sim 4 \mathrm{~h}$ ) to result in the ionospheric signatures of open flux tubes (i.e. FTEs) in both the pre- and post-noon sectors. This conclusion is consistent with previous studies of reconnection process employing data from HF coherent radars that have suggested spatially extended reconnection patches on the dayside magnetopause (e.g. Milan et al., 2000; McWilliams et al., 2000).

We propose to investigate further intervals where interhemispheric observations of the ionospheric signatures of
FTEs can be combined with in situ observations of FTEs at the dayside magnetopause. It would be particularly interesting to identify intervals when the Cluster spacecraft are located closer to the noon-midnight meridian or when the dawn-dusk component of the IMF is less significant, in order to study the interhemispheric timing of the ionospheric response to bursts of reconnection at the magnetopause in more detail.

Acknowledgements. During the course of this study Drs. Jackie Davies and James Wild were supported by PPARC grant number PPA/G/O/2001/0014. Prof. Stan Cowley was supported by a PPARC Senior Fellowship (grant number PPAN/N/S/2000/00197). Prof. N. Sato and Dr. A. S. Yukimatu were supported by a JSPS grant for scientific research (grant number A:11304029). The CUTLASS HF radars are deployed and operated by the University of Leicester, and are jointly funded by the UK Particle Physics and Astronomy Research Council (grant number PPA/R/R/1997/00256), the Finnish Meteorological Institute, and the Swedish Institute of Space Physics. The Syowa HF radars are deployed and operated by National Institute of Polar Research, and funded by the Ministry of Education, Culture, Sports, Science and Technology of Japan. We also thank all those SuperDARN PIs who provided radar data and Norman Ness and the ACE Science Center for providing the ACE magnetic field data presented in Fig. 3. JAW also thanks Dr. A. S. Rodger for helpful discussions on this subject.

Topical Editor T. Pulkkinen thanks P. E. Sandholt and another referee for their help in evaluating this paper.

\section{References}

Balogh, A., Dunlop, M. W., Cowley, S. W. H., Southwood, D. J., Thomlinson, J. G., Glassmeier, K.-H., Musmann, G., Lühr, H., Buchert, S., Acuña, M. H., Fairfield, D. H., Slavin, J. A., Riedler, W., Schwingenschuh, K., and Kivelson, M. G.: The Cluster magnetic fields investigation, Space Sci. Rev., 79, 65-91, 1997.

Balogh, A., Carr, C. M., Acuña, M. H., Dunlop, M. W., Beek, T. J., Brown, P., Fornaçon, K.-H., Georgescu, E., Glassmeier, K.-H., Harris, J., Musmann, G., Oddy, T., and Schwingenschuh, K.: The Cluster Magnetic Field Investigation: overview of in-flight performance and initial results, Ann. Geophysicae, 19, 1207-1217, 2001.

Berchem, J. and Russell, C. T.: Flux transfer events on the magnetopause: spatial distribution and controlling factors, J. Geophys. Res., 89, 6698, 1984.

Burch, J. L., Reiff, P. H., Menietti, J. D., Heelis, R. A., Hanson, W. B., Shawhan, S. D., Shelly, E. G., Sugiura, M., Weimer, D. R., and Winningham, J. D.: IMF $B_{Y}$-dependent plasma flow and Birkeland currents in the dayside magnetosphere, 1, Dynamics Explorer observations, J. Geophys. Res., 90, 1577-9415, 1985.

Cowley, S. W. H.: The causes of convection in the Earth's magnetosphere - a review of developments during the IMS, Rev. Geophys. Space Phys., 20, 531-565, 1982.

Cowley, S. W. H.: The impact of recent observations on theoretical understanding of solar wind-magnetosphere interactions, J. Geomag. Geoelectr., 38, 1223-1256, 1986.

Cowley, S. W. H. and Owen, C. J.: A simple illustrative model of open flux tube motion over the dayside magnetopause, Planet. Space Sci., 37, 1461-1475, 1989. 
Cowley, S. W. H. and Lockwood, M.: Excitation and decay of solar wind-driven flows in the magnetosphere-ionosphere system, Ann. Geophysicae, 10, 103-15, 1992.

Cowley, S. W. H., Freeman, M. P., Lockwood, M., and Smith, M. F.: The ionospheric signature of flux transfer events, in "Cluster: Dayside Polar Cusp", ESA SP-330, ESA, Noordwijk, The Netherlands, 105-112, 1991.

Davies, J. A., Yeoman, T. K., Rae, I. J., Milan, S. E., Lester, M., Lockwood, M., and McWilliams, K. A.,: Ground-based observations of the auroral zone and polar cap ionospheric responses to dayside transient reconnection, Ann. Geophysicae, 20, 781-794, 2002.

Elphic, R. C., Lockwood, M., Cowley, S. W. H., and Sandholt, P. E.: Flux transfer events at the magnetopause and in the ionosphere, Geophys. Res. Lett., 17, 2241-2244, 1990.

Farrugia, C. J., Rijnbeek, R. P., Saunders, M. A., Southwood, D. J., Rodgers, D. J., Smith, M. F., Chaloner, C. P., Hall, D. S., Christiansen, P. J., and Woolliscroft, L. J. C.:A multi-instrument study of flux transfer event structure, J. Geophys. Res., 98, 14465$14477,1988$.

Feldstein, Y. I. and Starkov, G. V.: Dynamics of auroral belt and geomagnetic disturbances, Planet. Space Sci., 15, 209-229, 1967.

Greenwald, R. A., Baker, K. B., Dudeney, J. R., Pinnock, M., Jones, T. B., Thomas, E. C., Villain, J.-P., Cerisier, J.C., Senior, C., Hanuise, C., Hunsucker, R. D., Sofko, G., Koehler, J., Nielsen, E., Pellinen, R., Walker, A. D. M., Sato, N., and Yamagishi, H.: Darn/SuperDARN: a global view of the dynamics of highlatitude convection, Space Sci. Rev, 71, 761-796, 1995.

Haerendel, G., Paschmann, G., Sckopke, N., Rosenbauer, H., and Hedgecock, P. C.: The frontside boundary layer of the magnetopause and the problem of reconnection, J. Geophys. Res., 83, 3195-216, 1978.

Heelis, R. A.: The effects of interplanetary magnetic field orientation on dayside high-lattude ionospheric convection, J. Geophys. Res., 89, 2873-2880, 1984.

Johnstone, A. D., Alsop, C., Burge, S., Carter, P. J., Coates, A. J., Coker, A. J., Fazakerley, A. N., Grande, M., Gowen, R. A., Gurgiolo, C., Hancock, B. K., Narheim, B., Preece, A., Sheather, P. H., Winningham, J. D., and Woodliffe, R. D.: PEACE: A Plasma Elctron And Current Instrument, Space Sci. Rev., 79, 351-398, 1997.

Kawano, H. and Russell, C. T.: Survey of flux transfer events observed with the ISEE 1 spacecraft: dependence on the interplanetary magnetic field, J. Geophys. Res., 102, 11 307-11 313, 1997.

Khan, H. and Cowley, S. W. H.: Observations of the response time of high latitude ionospheric convection to variations in the interplanetary magnetic field using EISCAT and IMP-8 data, Ann. Geophysicae, 17, 1306-1335, 1999.

Lockwood, M., Sandholt, P. E., Cowley, S. W. H., and Oguti, T.: Interplanetary field control of dayside auroral activity and the transfer of momentum across the dayside magnetopause, Planet. Space Sci., 37, 1347-1365, 1989.

Lockwood, M., Cowley, S. W. H., Sandholt, P. E., and Lepping, R. P.: The ionospheric signatures of flux transfer events and solar wind dynamic pressure changes, J. Geophys. Res., 95, 17 113$17135,1990$.

Lockwood, M., Moen, J., Cowley, S. W. H., Farmer, A. D., Løvhaug, U. P., Lühr, H., and Davda, V. N.: Variability of dayside convection and motions of the cusp/cleft aurora, Geophys. Res. Lett., 20, 1011-1014, 1993.

McComas, D. J., Bame, S. J., Barker, P., Feldman, W. C., Phillips, J. L., Riley, P., and Griffee, J. W.: Solar Wind Electron Proton
Alpha Monitor (SWEPAM) for the Advanced Composition Explorer, Space Sci. Rev., 86, 563-612, 1998.

McHenry, M. A. and Clauer, C. R.: Modeled ground magnetic signatures of flux transfer events, J. Geophys. Res., 92, $11231-$ $11240,1987$.

McWilliams, K. A., Yeoman, T. K., and Provan, G.: A statistical study of dayside pulsed ionospheric flows as seen by the CUTLASS Finland HF radar, Ann. Geophysicae, 18, 445-453, 2000.

Milan, S. E., Lester, M., Greenwald, R. A., and Sofko, G.: The ionospheric signature of transient dayside reconnection and the associated pulsed convection return flow, Ann. Geophysicae, 17, 1166-1171, 1999.

Milan, S. E., Lester, M., Cowley, S. W. H., and Brittnacher, M. Convection and auroral response to a southward turning of the IMF: Polar UVI, CUTLASS, and IMAGE signatures of transient magnetic flux transfer at the magnetopause, J. Geophys. Res., 105, 15 741-15 756, 2000.

Moses, J. J., Siscoe, G. L., Crooker, N. U., and Gorney, D. J.: IMF By and day-night conductivity effects in the expanding polar cap convection model, J. Geophys. Res., 92, 1193-1198, 1987.

Neudegg, D. A., Yeoman, T. K., Cowley, S. W. H., Provan, G., Haerendel, G., Baumjohann, W., Auster ,U., Fornaçon, K.-H., Georgescu, E., and Owen, C. J.: A flux transfer event observed at the magnetopause by the Equator-S spacecraft and in the ionosphere by the CUTLASS HF radar, Ann. Geophysicae, 17, 707$711,1999$.

Neudegg, D. A., Cowley, S. W. H., Milan, S. E., Yeoman, T. K., Lester, M., Provan, G., Haerendel, G., Baumjohann, W., Nikutowski, B., Büchner, J., Auster, U., Fornaçon, K.-H., and Georgescu, E.: A survey of magnetopause FTEs and associated flow bursts in the polar ionosphere, Ann. Geophysicae, 18, 416435, 2000.

Neudegg, D. A., Cowley, S. W. H., McWilliams, K. A., Lester, M., Yeoman, T. K., Sigwarth, J., Haerendel, G., Baumjohann, W., Auster, U., Fornaçon, K.-H., and Georgescu, E.: The UV aurora and ionospheric flows during flux transfer events, Ann. Geophysicae, 19, 179-188, 2001.

Owen, C. J., Fazakerley, A. N., Carter, P. J., Coates, A. J., Krauklis, I. C., Szita, S., Taylor, M. G. G. T., Travnicek, P., Watson, G., Wilson, R. J., Balogh, A., and Dunlop, M. W.: Cluster PEACE observations of electrons during magnetospheric flux transfer events, Ann. Geophysicae, 19, 1509-1522, 2001.

Paschmann, G., Haerendel, G., Papamastorakis, I., Sckopke, N., Bame, S. J., Gosling, J. T., and Russell, C. T.: Plasma and magnetic field characteristics of flux transfer events, J. Geophys. Res., 87, 2159-2168, 1982.

Pinnock, M., Rodger, A. S., Dudeney, J. R., Baker, K. B., Newell, P. T., Greenwald, R. A., and Greenspan, M. E.: Observations of an enhanced convection channel in the cusp ionosphere, J. Geophys. Res., 98, 3767-3776, 1993.

Pinnock, M., Rodger, A. S., Dudeney, J. R., Rich, F., and Baker, K. B.: High spatial and temporal resolution observations of the ionospheric cusp, Ann. Geophysicae, 13, 919-925, 1995.

Provan, G., Yeoman, T. K., and Milan, S. E.: CUTLASS Finland radar observations of the ionospheric signatures of flux transfer events and the resulting plasma flows, Ann. Geophysicae, 16, 1411-1422, 1998.

Provan, G. and Yeoman, T. K.: Statistical observations of the MLT, latitude and size of pulsed ionospheric flows with the CUTLASS Finland radar, Ann. Geophysicae, 17, 855-867, 1999.

Provan, G., Yeoman, T. K., and Cowley, S. W. H.: The influence of the IMF $B_{y}$ component on the location of pulsed flows in the day- 
side ionosphere observed by an HF radar, Geophys. Res. Lett., 26, 521-524, 1999.

Rème, H., Bosqued, J.-M., Sauvaud, J. A., Cros, A., Dandouras, J., Aoustin, C., Bouyssou, J., Camus, Th., Cuvilo, J., Martz, C., M'Edale, J. L., Perrier, H., Romefort, D., Rouzaud, J., D'uston, C., Möbius, E., Crocker, K., Granoff, M., Kistler, L. M., Popecki, M., Hovestadt, D., Klecker, B., Paschmann, G., Scholer, M., Carlson, C. W., Curtis, D. W., Lin, R. P., McFadden, J. P., Formisano, V., Amata, E., Bavassano-Cattaneo, M. B., Baldetti, P., Belluci, G., Bruno, R., Chionchio, G., Di Lellis, A., Shelley, E. G., Ghielmetti, A. G., Lennartsson, W., Korth, A., Rosenbauer, H., Lundin, R., Olsen, S., Parks, G. K., McCarthy, M., and Balsiger, H.: The Cluster Ion Spectrometry (CIS) Experiment, Space Sci. Rev., 79, 303-350, 1997.

Rème H., Aoustin, C., Bosqued, J.-M., Dandouras, I., Lavraud, B., Sauvaud, J. A., Barthe, A., J. Bouyssou, J., Camus, Th., CoeurJoly, O., Cros, A., Cuvilo, J., Ducay, F., Garbarowitz, Y., Medale, J. L., Penou, E., Perrier, H., Romefort, D., Rouzaud, J., Vallat, C., Alcaydé, D., Jacquey, C., Mazelle, C., d’Uston, C., Möbius, E., Kistler, L. M., Crocker, K., Granoff, M., Mouikis, C., Popecki, M., Vosbury, M., Klecker, B., Hovestadt, D., Kucharek, H., Kuenneth, E., Paschmann, G., Scholer, M., Sckopke, N., Seidenschwang, E., Carlson, C. W., Curtis, D. W., Ingraham, C., Lin, R. P., McFadden, J. P., Parks, G. K., Phan, T., Formisano, V., Amata, E., Bavassano-Cattaneo, M. B., Baldetti, P., Bruno, R., Chionchio, G., Di Lellis, A., Marcucci, M. F., Pallocchia, G., Korth, A., Daly, P. W., Graeve, B., Rosenbauer, H., Vasyliunas, V., McCarthy, M., Wilber, M., Eliasson, L., Lundin, R., Olsen, S., Shelley, E. G., Fuselier, S., Ghielmetti, A. G., Lennartsson, W., Escoubet, C. P., Balsiger, H., Friedel, R., Cao, J-B., Kovrazhkin, R. A., Papamastorakis, I., Pellat, R., Scudder, J., and Sonnerup, B.: First multispacecraft ion measurements in and near the Earth's magnetosphere with the identical Cluster ion spectrometry (CIS) experiment, Ann. Geophysicae, 19, 13031354, 2001.

Rijnbeek, R. P., Cowley, S. W. H., Southwood, D. J., and Russell, C. T.: A survey of dayside flux transfer events observed by ISEE 1 and 2 magnetometers, J. Geophys. Res., 89, 786-800, 1984.

Rodger, A. S. and Pinnock, M.: The ionospheric response to FTEs: the first few minutes, Ann. Geophysicae, 15, 685-691, 1997.

Ruohoniemi, J. M. and Greenwald, R. A.: Statistical patterns of high-latitude convection obtained from Goose Bay HF radar observations, J. Geophys. Res., 101, 21 746-21 763, 1996.

Ruohoniemi, J. M. and Baker, K. B.: Large-scale imaging of highlatitude convection with Super Dual Auroral Radar Network HF radar observations, J. Geophys. Res., 20 797-20 811, 103, 1998.

Russell, C. T. and Elphic, R. C.: Initial ISEE magnetometer results: magnetopause observations, Space Sci. Rev., 22, 681-715, 1978.

Russell, C. T. and Elphic, R. C.:ISEE observations of flux transfer events at the dayside magnetopause, Geophys. Res. Lett., 6, 3336, 1979.

Sandholt, P. E., Lockwood, M., Oguti, T., Cowley, S. W. H., Freeman, K. S. C., Lybekk, B., Egeland, A., and Willis, D. M.: Mid- day auroral breakup events and related energy and momentum transfer from the magnetosheath, J. Geophys. Res., 95, 10391060, 1990.

Saunders, M. A., Russell, C. T., and Sckopke, N.: Flux transfer events: scale size and interior structure, Geophys. Res. Lett., 11, 131-134, 1984.

Scholer, M.: Magnetic flux transfer at the magnetopause based on singe X-line bursty reconnection, Geophys. Res. Lett., 15, 291294, 1988.

Shue, J.-H., Chao, J. K., Fu, H. C., Russell, C. T., Song, P., Khurana, K. K., and Singer, H. J.: A new functional form to study the solar wind control of the magnetopause size and shape, J. Geophys. Res., 102, 9497-9511, 1997.

Smith, C. W., Acuña, M. H., Burlaga, L. F., L'Heureux, J., Ness, N. F., and Scheifele, J.: The ACE Magnetic Fields Experiment, Space Sci. Rev., 86, 613-632, 1998.

Sonnerup, B. U. O. and Cahill, L. J.: Magnetopause structure and attitude from Explorer 12 observations, J. Geophys. Res., 72, 171-183, 1967.

Southwood, D. J.: Theoretical aspects of the ionospheremagnetosphere-solar wind coupling, Adv. Space Res., 5, 7-14, 1985.

Southwood, D. J.: The ionospheric signature of flux transfer events, J. Geophys. Res., 92, 3207-3213, 1987.

Southwood, D. J., Farrugia, C. J., and Saunders, M. A.: What are flux transfer events?, Planet. Space Sci., 36, 503-508, 1988.

Stone, E. C., Frandsen, A. M., Mewaldt, R. A., Christian, E. R., Marglies, D., Ormes, J. F., and Snow, F.: The Advanced Composition Explorer, Space Sci. Rev., 86, 1-22, 1998.

Thorolfsson, A., Cerisier, J.C., Lockwood, M., Sandholt, P. E., Senior, C., and Lester, M.: Simultaneous optical and radar signatures of poleward-moving auroral forms, Ann. Geophysicae, 18, 1054-1066, 2000.

Tsyganenko, N. A.: Modeling the Earth's magnetospheric magnetic field within a realistic magnetopause, J. Geophys. Res., 100, 5599-5612, 1995.

Tsyganenko, N. A.: Effects of the solar wind conditions on the global magnetospheric configuration as deduced from data-based field, in: "Proc. 3rd Internat. Conf. on Substorms (ICS-3)", ESA SP-389, 181-185, 1996.

van Eyken, A. P., Rishbeth, H., Willis, D. M., and Cowley, S. W. H.: Initial EISCAT observations of plasma convection at invariant latitudes $70^{\circ}-77^{\circ}$, J. Atmos. Terr. Phys., 46, 635-641, 1984.

Wei, C. Q. and Lee, L. C.: Ground magnetic signatures of moving elongated plasma clouds, J. Geophys. Res., 95, 2405-2418, 1990.

Wild, J. A., Cowley, S. W. H., Davies, J. A., Khan, H., Lester, M., Milan, S. E., Provan, G., Yeoman, T. K., Balogh, A., Dunlop, M. W., Fornaçon, K.-H., and Georgescu, E.: First simultaneous observations of flux transfer events at the high-latitude magnetopause by the Cluster spacecraft and pulsed radar signatures in the conjugate ionosphere by the CUTLASS and EISCAT radars, Ann. Geophysicae, 19, 1491-1508, 2001. 